\title{
II. Aufbau einer zentralisierten Justizverwaltung: die Überleitung der Länderkompetenzen auf das Reich
}

\author{
1. Die geteilte Justizhoheit und die Zuständigkeiten des \\ Reichsjustizministeriums bis zur nationalsozialistischen \\ Machtergreifung 1933
}

Das Ministerium, dem Gürtner bei der nationalsozialistischen Machtübernahme vorstand, war auf Grund seiner begrenzten Zuständigkeit das kleinste der Reichsministerien der Weimarer Republik. Im Gegensatz zu vielen der traditionsreichen Justizministerien der einzelnen Länder konnte es erst auf eine fünf Jahrzehnte währende Geschichte zurückblicken. Seine Geburtsstunde hatte im gleichen Jahr geschlagen, in dem das deutsche Kaiserreich daranging, eine einheitliche Gerichtsorganisation und ein einheitliches Zivil- und Strafverfahren zu schaffen: am 1. Januar 1877 wurde die Rechtsabteilung des Reichskanzleramts als selbständiges „Reichsjustizamt“ eingerichtet. Bis auf die Ausarbeitung eines einheitlichen Strafgesetzbuches, das 1871 schon vor der Errichtung des Justizamtes geschaffen worden war, war dieses Amt um die Jahrhundertwende unter Staatssekretär Nieberding an dem Gesetzgebungswerk zur Vereinheitlichung des Bürgerlichen Rechts (1896), Handels- und Grundbuchrechts (1897), der freiwilligen Gerichtsbarkeit (1898) sowie des Wechselrechts (1908) und anderer Rechtsmaterien maßgeblich beteiligt. Auch die Verwaltung des 1877 errichteten Reichspatentamtes sowie des Reichsgerichts, das 1879 als oberster Gerichtshof und letzte Instanz im Reich gegründet worden war, und die Leitung der Reichsanwaltschaft unterstanden diesem Amt. Im Gegensatz zur Gesetzgebung auf verschiedenen Gebieten der Rechtspflege, die die Verfassung von 1871 dem Reich zugesprochen hatte, waren jedoch die Gerichte, Staatsanwaltschaften und Vollzugsanstalten und ihre Verwaltung, die Begnadigung - sofern sie nicht Fälle von Hoch- und Landesverrat betraf -, ferner der Erlaß ergänzender Rechts- und Verwaltungsvorschriften zur Ausführung der Reichsgesetze und die nicht ausdrücklich dem Reich vorbehaltene Gesetzgebung in der ausschließlichen Zuständigkeit der Bundesstaaten geblieben. Die Trennung von Gesetzgebung und Justizverwaltung hatte vor allem den Nachteil, daß das Reichsjustizamt, das die Reichsgesetze für die Gesetzgebung ausarbeitete, keine unmittelbare Anschauung von den Notwendigkeiten der Praxis gewinnen und - abgesehen von der Möglichkeit der Reichsaufsicht, die dem Kaiser und dem Bundesrat zustand - die Durchführung dieser Gesetze nicht beeinflussen konnte.

Diese Teilung der Justizhoheit blieb auch in der Weimarer Republik zwischen Reich und Ländern bestehen. Zwar gab es Bestrebungen, die gesamte Justiz ein- 
schließlich der Justizverwaltung in der Hand des Reiches zu vereinigen, die Rechtspflege - wie es damals hieß - zu „verreichlichen“. Schon bei den Verfassungsberatungen in Weimar brachte der Abgeordnete der Deutschen Demokratischen Partei Dr. Ablaß einen entsprechenden Antrag ein ${ }^{1}$, der bei dem erheblichen Widerstand vor allem der preußischen und der bayerischen Regierung - auch der Kommissar des Reichsjustizministeriums sprach sich im Verfassungsausschuß dagegen aus - von der Nationalversammlung abgelehnt wurde. Anfang 1928 erneuerte die Demokratische Partei ihren Anlauf mit dem Antrag im Reichstag, daß die Reichsregierung die Übernahme der Justizverwaltungen der Länder auf das Reich baldigst prüfen und dem Parlament darüber Bericht erstatten möge. Dieser Antrag wurde bei der Beratung des Etats des Reichsjustizministeriums am 30. Januar 1928 im Hammelsprung mit $172: 134$ Stimmen abgelehnt. ${ }^{2}$ Im gleichen Jahr wurde die Verreichlichung der Justiz auch auf der Tagung des deutschen Richterbundes in Weimar und auf dem 35. Deutschen Juristentag in Salzburg erörtert und durch entsprechende Entschließungen bejaht. Als sich in der zweiten Hälfte der zwanziger Jahre die Finanzlage der Länder verschlechterte, erklärten sich zwar einzelne kleinere Länder bereit, die Justizverwaltung aus Ersparnisgründen an das Reich abzugeben. ${ }^{3}$ Das Reich lehnte jedoch eine solche unorganische Lösung der Übernahme einzelner Landesjustizverwaltungen ab.

Der Widerstand der Länder gegen eine Verreichlichung der Justiz war vom föderalistischen Standpunkt aus verständlich: hatten sie durch die Regelung der Weimarer Verfassung bereits die Gesetzgebung für zahlreiche Materien, die Zuständigkeit für die Armee, die Finanzverwaltung, die Eisenbahnverwaltung, die Reservatrechte im Postund Telegraphenwesen verloren, so mußte die Abtretung der Justizverwaltung an das Reich ihre Eigenstaatlichkeit in noch erheblicherem Maße aushöhlen. An Sachargumenten führten die Landesregierungen an, daß die Personalangelegenheiten der Justiz auf regionaler Ebene weit besser geregelt werden könnten als von einer Reichszentrale aus, daß vor allem die Richter ihrem Heimatvolk verbunden bleiben müßten, daß innerhalb der Länder die Verbindung zwischen einer verreichlichten Justiz und den übrigen Landesverwaltungen gestört werde und daß schließlich die zentrale Reichsstelle mit Verwaltungsgeschäften überlastet werde und damit ihrer eigentlichen Aufgabe nicht gerecht werden könne. Daß die Frage einer unitarisch oder föderalistisch organisierten Justiz im Grunde keine sachliche oder wirtschaftliche, sondern eine politische Entscheidung war, hatte Gürtner als damaliger bayerischer Justizminister klar erkannt, als er am 21. Februar 1929 in der Debatte über den Justizetat im Bayerischen Landtag ausführte:

„Ich behaupte, die Frage der Übernahme der Justiz auf das Reich ist eine rein politische Frage ... Wer den Einheitsstaat fordert, und zwar in dem Sinne, daß es außerhalb der Reichsgewalt eine Staatsgewalt im Deutschen Reiche nicht geben soll, der braucht die Forderung nach Verreichlichung der Justiz gar nicht zu begründen; denn die Justiz ist eine der wesentlichsten Bestandteile der Staatsverwaltung [gemeint: Staatsgewalt].“4

1 Protokoll S.353, vgl. Anschütz, Die Verfassung des Deutschen Reichs, 8. Aufl., Berlin 1928, S. 281.

2 Vgl. Verhandlungen des Reichstags, III. Wahlperiode 1924, Bd.394, S. 12515.

3 Über das Angebot der beiden Mecklenburg und Hessens im Jahre 1932 s. H. Brüning, Memoiren 1918-1934, Stuttgart 1970, S. 569 f.; dort auch über Brünings Pläne, die Justizverwaltung aller Länder durch Notverordnung auf das Reich zu übertragen.

4 Vgl. Verhandlungen des Bayerischen Landtags 1928/29, 23. Sitzung vom 21.2.29, Sten. Berichte, Bd.I, S.682; auch zitiert in Gürtners Rede am 12.1.35 im Münchener Justizpalast anläßlich der Übernahme der bayerischen Justizverwaltung (DJ 1935, S.81), dort richtig „Staatsgewalt“ statt „Staatsverwaltung“. 
Die eigentliche Aufgabe des Reichsjustizministeriums - wie es seit März 1919 offiziell genannt wurde ${ }^{5}$ - blieb auch in der Weimarer Zeit die Gesetzgebungsarbeit, die allerdings gegenüber der Zeit des Kaiserreichs erheblich zunahm, da sie sich auf dem Gebiet der Rechtspflege de facto immer stärker auf die Reichsebene verlagerte. Entsprechend seiner Aufgabe, die Gesetzgebung und die internationalen Beziehungen auf den verschiedenen Rechtsgebieten wahrzunehmen, war das Reichsjustizministerium zum Zeitpunkt der nationalsozialistischen Machtergreifung in drei Abteilungen gegliedert, denen je ein Ministerialdirektor vorstand:

Abt. I: Bürgerliches Recht, bürgerliche Rechtspflege,

Abt. II: Strafrecht, Strafrechtspflege und Strafvollzug,

Abt. III: Handelsrecht, Wirtschafts- und Verkehrsrecht, öffentliches Recht.

Dem Staatssekretär - seit 1931 Dr. Franz Schlegelberger, der diesen Posten auch 1933 beibehielt - waren außerdem die Referate für die Personal-, Haushalts- und sonstigen Verwaltungsangelegenheiten des Ministeriums, des Reichsgerichts und des Reichspatentamtes unmittelbar unterstellt. An Beamten zählte das Ministerium damals außer dem Staatssekretär und den genannten 3 Ministerialdirektoren 12 Ministerialräte, 5 Oberregierungsräte, 6 auftragsweise verwendete Richter und Staatsanwälte, 1 Ministerialbürodirektor, 16 Beamte des gehobenen, 9 des mittleren und 20 des einfachen Dienstes ${ }^{6}$; dazu kamen eine Anzahl von Angestellten und Arbeitern. Seinen Sitz hatte das Reichsjustizministerium in der Voßstraße 4/5 im Berliner Regierungsviertel, einem wuchtigen Sandsteinbau, in dem vorher auch das Reichsjustizamt untergebracht gewesen war und der 1937 bei der Erweiterung der Reichskanzlei abgebrochen werden sollte.

\section{Die Rolle Hans Franks als „Reichsjustizkommissar“ 1933}

Mit der Machtübernahme der Nationalsozialisten, die die Beseitigung des föderativen Staatsaufbaus und die Errichtung eines zentralisierten Einheitsstaates auf ihre Fahnen geschrieben hatten, war die politische Voraussetzung für eine Übernahme der Justizverwaltung durch das Reich gegeben. Vor der Vereinheitlichung der Justiz auf dem staatlichen Sektor sollte jedoch im Jahre 1933 zunächst die organisatorische und ideologische Gleichschaltung der Justizangehörigen und ihrer Berufsvereinigungen durch die nationalsozialistische Bewegung erfolgen. Der am 22. April 1933 zum „Reichskommissar für die Gleichschaltung der Justiz in den Ländern und für die Erneuerung der Rechtsordnung“ ernannte Führer des „Bundes Nationalsozialistischer Deutscher Juristen“ (BNSDJ), Leiter der Rechtsabteilung in der Reichsleitung der NSDAP,

s S. Erlaß betr. die Errichtung und Bezeichnung der obersten Reichsbehörden v. 21.3.1919 (RGBI., S.327).

6 Min.Rat F. Sauer, Das Reichsjustizministerium, Schriften der Hochschule für Politik H. 36/37, Berlin 1939, S. 7. Dem Ministerium war damals noch das sogenannte Auslandsstrafregister (Strafregister für Personen, deren Geburtsort außerhalb des Reichsgebiets lag, zweifelhaft oder nicht zu ermitteln war) mit rund 20 Beamten des gehobenen Dienstes angegliedert. Es wurde durch AV des RJM v. 2.5.1936 (DJ S. 702) abgetrennt und bei der Staatsanwaltschaft beim Volksgerichtshof geführt. Ab 1.4.1937 wurde es gemäß AV d. RJM (DJ S.415) der Staatsanwaltschaft beim Kammergericht angegliedert. 
Rechtsanwalt Dr. Hans Frank II, beseitigte im Laufe des Jahres die selbständigen Berufsverbände und Standesvereinigungen der Juristen und baute den BNSDJ als einen der NSDAP angeschlossenen Verband zur Standesorganisation aller Juristen aus. ${ }^{1}$ Hierbei geriet er in rivalisierenden Gegensatz zu dem preußischen Justizminister Hanns Kerrl - einem radikalen Nationalsozialisten, der im März 1933 vom mittleren Justizbeamten (Oberrentmeister) zum Chef der Justizverwaltung des größten deutschen Landes aufgestiegen war -, der von Preußen ausgehend seinerseits eine Einheitsorganisation aller deutschen Justizbeamten schaffen und sie „als eine der maßgebenden Säulen dem Deutschen Beamtenbund“ anschließen wollte. ${ }^{2}$ Frank verstand es jedoch, diese Einmischung in die von ihm beanspruchte Domäne mit Erfolg abzuwehren. Ein Glückwunschschreiben Hitlers vom 30. März 1933, in dem dieser ihm zu den Fortschritten beim Aufbau des BNSDJ gratulierte und das mit den Sätzen endete:

„Alle mit dem Recht verwurzelten Berufsstände und Amtsträger werden daher in der Front des Deutschen Rechtes des Bundes Nationalsozialistischer Deutscher Juristen als Standesgruppe in den kommenden ständischen Aufbau überführt werden können. Ihre Ihnen diesbezüglich erteilten Vollmachten bestätige ich hiermit vollinhaltlich “3,

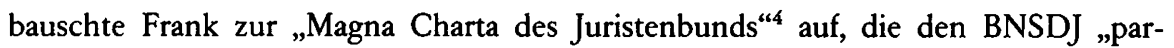
teiamtlich und reichsamtlich" zur alleinigen Standesorganisation aller deutschen Juristen bestimmte. ${ }^{5}$ In einer Bekanntmachung vom 8. Juni 1933 stellte er fest, daß „alle Anweisungen irgendwelcher Dienststellen, die dieser Anordnung des Führers der NSDAP zuwiderlaufen“, insbesondere „die Pläne der preußischen Justizverwaltung, wie sie in dem Rundschreiben ${ }^{6}$ an die preußischen Justizbeamten geäußert" wurden, „gegenstandslos" seien. Für die Justizbeamtenschaft bestehe „somit weder Veranlassung noch Verpflichtung, der Justizfachschaft im Beamtenbund beizutreten “. ${ }^{7}$ Es gelang Frank, diesen Grundsatz auch in einer Vereinbarung mit dem stellvertretenden Reichskommissar für Beamten-Organisationen Neef durchzusetzen, die gleichzeitig bestimmte, daß rechts- und staatswissenschaftlich vorgebildete Beamte dem BNSDJ

\section{Anmerkungen zu Kapitel II.2}

${ }^{1}$ Vgl. dazu H. Weinkauff, Die deutsche Justiz und der Nationalsozialismus, Bd. I, Stuttgart 1968, S. 102 ff., und H. Wrobel, Der Deutsche Richterbund im Jahre 1933. Skizze eines Ablaufs (Kritische Justiz 1982, S. 323 ff.).

${ }^{2}$ S. „Völkischer Beobachter“ (VB) v. 8.6.1933, Südd. Ausgabe, S.1.

${ }^{3}$ Text des Schreibens in der von Frank herausgegebenen Zeitschrift des BNSDJ „Deutsches Recht" (DR) 1933, S. 60.

4 So in: H. Frank, Nationalsozialistisches Handbuch für Recht und Gesetzgebung, München 1935, S. 1569.

5 Vgl. Anordnung Franks v. 26.7.1933 (DR 1933, S.90).

${ }^{6}$ Gemeint ist Kerrls RV v. 31.5.33 an die preuß. Justizbehörden mit der Aufforderung, ihm innerhalb einer Woche die Beitrittserklärungen aller Justizbeamten zu übersenden, die Mitglieder der „Fachgruppe Justiz im Deutschen Beamtenbund" werden wollten und von denen aus jedem OLGBezirk eine bestimmte Anzahl an der Gründungsversammlung teilnehmen sollten, die für den 12.6.33 im Sitzungssaal des Preußischen Landtages vorgesehen war. Die Fachgruppe sollte die „Kampffront“ aller Justizbeamten bilden, „die in dieser organisierten Zusammenfassung sich dem Führer der nationalsozialistischen Bewegung als Soldaten zur Verfügung stellen“. Wie Sts. Freisler als Landesfachgruppenleiter für Preußen auf dieser Gründungsversammlung mitteilte, waren von den 47500 preuß. Justizbeamten ( 31000 planmäßige Beamte, 4000 Hilfsbeamte, 2500 Assessoren ohne Planstelle und 10000 Referendare) binnen zehn Tagen 29168 der Fachgruppe beigetreten. Vgl. dazu U. Hamann, Das Oberlandesgericht Celle im Dritten Reich. Justizverwaltung und Personalwesen (in: Festschrift zum 275jährigen Bestehen des Oberlandesgerichts Celle, Celle 1986, S. $146 \mathrm{ff}$.), S. $213 \mathrm{f}$.

7 VB v. 10.6.1933, Südd. Ausgabe, S.3; vgl. auch Franks Rundfunkrede v. 8.6.1933 (DR 1933, S.66), ferner seine Anordnungen für den BNSDJ 7/1933 und 20/1933 (DR 1933, S. 26 und 90) sowie seinen nochmaligen Hinweis im VB v. 30.7.1933, S.3. 
eingegliedert werden mußten. ${ }^{8}$ Diese Auseinandersetzung bei der „Sammeltätigkeit des menschlichen Materials der deutschen Juristen" "9ührte zu einer tiefgreifenden Gegnerschaft zwischen Frank und Kerrl, die sich trotz der Ernennung Kerrls zum stellvertretenden Führer des BNSDJ ${ }^{10}$ auch auf die Verreichlichung im staatlichen Bereich ausdehnte ${ }^{11}$ : in den folgenden Monaten sollten sich beide in zunehmendem Maße als Rivalen bei ihrem Streben nach dem Posten des Reichsjustizministers ansehen, mit dessen Neubesetzung sie nach dem Tod Hindenburgs rechneten. ${ }^{12}$ Kerrl konnte jedenfalls nicht verhindern, daß Frank mit der am 1. Juni 1933 gegründeten "Deutschen Rechtsfront" - einem Gebilde politischen Charakters ohne eigene Rechtspersönlichkeit, deren organisatorischer Träger der BNSDJ war - sogar eine erweiterte Zusammenfassung aller mit dem Recht zusammenhängenden Berufe schuf. Der „Rechtsfront“ gehörten neben dem BNSDJ die gleichgeschalteten Berufsverbände der Sachverständigen, der Zwangsverwalter, Gerichtsvollzieher, Friedensrichter, Dolmetscher, Buchprüfer usw. an. Reichsjustizkommissar Frank wirkte ferner wesentlich bei der Gründung jener vom Staat geschaffenen und mit Rechtsfähigkeit ausgestatteten berufsständischen Organisationen mit, die - ohne selbst staatliche Behörden zu sein - vom Staat bestimmte Aufgaben übertragen bekamen: der Reichs-Rechtsanwaltskammer ${ }^{13}$, der Patentanwaltskammer ${ }^{14}$ und später auch der Reichsnotarkammer. ${ }^{15}$ Auf der Schlußkundgebung des Deutschen Juristentages in Leipzig am 3. Oktober 1933 appellierte Frank an die Reichsregierung, der nunmehr geschaffenen „Einheit des deutschen Juristenstandes“ möglichst bald auch die „Reichsvereinheitlichung der deutschen Justiz“ folgen zu lassen, und bot an, daß sich der BNSDJ dafür „mit seinen Vorarbeiten dem Gesetzgeber zur Verfügung“" stellen würde. ${ }^{16}$

${ }^{8}$ Vereinbarung vom 14.9.1933 (DR 1933, S.156; VB v. 20.9.1933, S.3). Die Unstimmigkeiten dauerten jedoch weiter an (vgl. Rundschreiben Neefs v. 13.12.1933 im VB v. 14.12.1933). Die Vereinbarung wurde von Neef wieder gekündigt, der die Erfassung auch der Justizbeamten im neu gegründeten Reichsbund der Deutschen Beamten forderte, da der BNSDJ keine beamtenpolitischen Belange vertrete (VB v. 30.12.1933, S.1 u. 2). Daraufhin ordnete Frank in seiner Eigenschaft als bayer. Justizminister an, daß sämtliche bayer. Justizbeamte bis 10.1.34 aus den Fachschaften des Beamtenbundes auszutreten hätten (Anordnung v. 27.12.33, Bayer. JMBl. 1934, S. 3). Eine endgültige Regelung erfolgte am 10.2.1934. Danach wurden rechts- und staatswissenschaftlich vorgebildete sowie alle sonstigen mit richterlichen Geschäften betrauten Justizbeamten sowie Amtsanwälte als Mitglieder des BNSDJ automatisch auch Mitglieder des Reichsbundes Deutscher Beamten, ohne zur Beitragszahlung für letzteren verpflichtet zu sein. Andere Justizbeamte, die dem BNSDJ beitraten, erhielten dagegen keine Beitragsbefreiung im Reichsbund (Deutsche Verwaltung, Organ der Fachgruppe Verwaltungsjuristen des BNSDJ 1934, S.30, vgl. auch die gemeinsame Bekanntmachung Fricks und Heß' v. 11.2.1934 im VB v. 12.2.1934, S.2).

9 So Frank in seiner Rede zur Gründung der „Front des Deutschen Rechts“ am 1.6.1933 in Hamburg (VB v. 8.6.1933, Beiblatt; auch: DR 1933, S.33 ff.).

10 Im November 1933. Freisler wurde zweiter Stellvertreter (vgl. DR 1933, S. 232). Während Frank in seiner Akademie für Deutsches Recht Freisler zum Vorsitzenden des Strafrechtsausschusses bestellte, fand er Kerrl neben dem lediglich repräsentativen Vorsitz des „Führerrates“ der Akademie mit dem politisch belanglosen Vorsitz im Ausschuß für Sparkassenwesen ab.

11 Vgl. im folgenden S.95, 102, $104 \mathrm{f} ., 144 \mathrm{ff}$.

12 Vgl. Aufz. Schlegelbergers über eine Unterredung mit Thierack am 24.11.33 (Akten des RJM, BA, Sign. R 22/4723)

13 S. G. v. 18.3.1933 (RGBI. I, S. 109, 120); später $\S \S 46$ ff. der Reichs-Rechtsanwaltsordnung v. 21. 2.1936 (RGBl. I, S. 107).

14 G. v. 28.9.1933 (RGBl. I, S.669).

15 G. v. 17.7.1934 (RGBl. I, S. 712); später $\$ \S 44$ ff. der Reichs-Notarordnung v. 13.2.1937 (RGBl. I, S. 191).

16 Deutscher Juristentag 1933. 4. Reichstagung des Bundes Nationalsozialistischer Deutscher Juristen e. V., Ansprachen und Fachvorträge, zusammengestellt und bearbeitet von R. Schraut, Berlin 1933, S.318. Die Reichsfachgruppe Notare im BNSDJ arbeitete den Entwurf einer Reichsnotariatsordnung aus. Auf dem Gebiet der Vereinheitlichung der Justizverwaltung ist jedoch eine beratende Mitwirkung des BNSDJ nicht festzustellen. 
Die Ernennung Franks zum „Reichsjustizkommissar“ hatte Gürtner bei Hitler angeregt. Offensichtlich suchte er damit zwei Ziele zu erreichen: Einmal wollte er den Aktivitäten Franks - der sich bei der Ernennung Gürtners zum Reichsjustizminister übergangen fühlte und nunmehr die neuen nationalsozialistischen Landesjustizchefs gegen das von „Reaktionären“ geleitete Reichsjustizministerium zu mobilisieren suchte - die Spitze nehmen und sie in die Bahn geordneter Staatsautorität lenken. Zum anderen wollte er sich bei der bevorstehenden Reform der Justizverwaltung und der Rechtsordnung die Mitwirkung dieses prominenten Parteijuristen sichern, der die Arbeit des Ministeriums gegenüber der Partei vertreten und mit ihr koordinieren konnte. Bei der Opposition der neuen Landesjustizchefs, die sich gerade in diesen Tagen gegen die ihnen zu „gemäßigte" reichsgesetzliche Regelung der Ausschaltung jüdischer Justizbeamter und Rechtsanwälte abzeichnete ${ }^{17}$, mußte Gürtner eine solche Unterstützung besonders willkommen sein. In einer Unterredung am 5. April schlug er Hitler daher vor, Frank mit seiner Stellvertretung als Reichsjustizminister zu betrauen. Die Verwirklichung dieses Gedankens hätte jedoch eine Änderung der Bestimmungen über die Stellvertretung der Reichsminister in der Geschäftsordnung der Reichsregierung erfordert ${ }^{18}$, vor der Hitler zurückscheute. Als Alternative empfahl Gürtner, Frank zum Reichskommissar zu bestellen, um damit „für die bevorstehende Neugestaltung des deutschen Rechtswesens eine wirksame und nach außen eindrucksvolle Verbindung $z$ wischen dem Reichsjustizministerium und der Rechtsabteilung der Nationalsozialistischen Partei zu schaffen“. Hitler stimmte zwar zu, hielt aber „die Sache für nicht so vordringlich“. Da jedoch Frank in einem Schreiben an Gürtner und schließlich nochmals in einem Telegramm vom 10. April auf seine baldige Ernennung drängte, Gürtner aber am Nachmittag dieses Tages den nach Berchtesgaden in Urlaub abfahrenden Hitler nicht mehr erreichte, legte der Reichsjustizminister in einem Schreiben an Hitler vom 11. April die Entwicklung nochmals dar und kündigte an, dem Kabinett bei der nächsten Gelegenheit den Vorschlag der Ernennung Franks zu unterbreiten. ${ }^{19}$ Frank, dem eine Abschrift des Briefes zugegangen war, dankte Gürtner telegrafisch am 13. April ,im Namen der NSDAP für den Vorschlag“, den er annehme. „Angesichts der ernstlich drohenden Zersplitterung des Reformvorgehens in den einzelnen Ländern“ bat er abermals ,um tunlichste Beschleunigung“. Eine Woche später hatte Frank eine Aussprache mit Hitler und telegrafierte dem Reichsjustizminister in dessen Auftrag, daß auch Hitler einverstanden sei. ${ }^{20}$ Daraufhin stellte Gürtner in der nächsten Kabinettssitzung am 22. April den Antrag, Hindenburg die Ernennung Franks zum „Reichskommissar für die Gleichschaltung der Justiz in den Ländern und für die Erneuerung der Rechtsordnung“ vorzuschlagen, der nach Gürtners Erläuterung „die einheitliche Durchführung der Reichsgesetze in den Ländern“ sichern und in dem künftigen Gremium des Reichsjustizministeriums, das die Reform

17 Vgl. dazu Kapitel III.1.a., S. 136 ff.

18 Nach $\S 16$ Abs. 2 der GeschO der RReg v. 3.5. 24 (RMBl. 1924, S. 173) konnte z. B. ein Reichsminister bei der Gegenzeichnung von Gesetzen, Verfügungen oder Anordnungen des Reichspräsidenten nur durch einen anderen Reichsminister vertreten werden. Erst durch die Änderung der GeschO v. 20.3.35 (RMBl. 1935, S. 423) durften auch die Staatssekretäre in Vertretung ihrer Minister mitzeichnen.

19 Vgl. - auch zur Unterredung v. 5.4.33 - Gürtners Schr. an Hitler nach Berchtesgaden v. 11.4.33 (Akten des RJM, BA, Sign. R 22/3168).

20 Vgl. Telegr. Franks v. 13. und 19.4.33 (a.a.O., Sign. R 22/4723). 
der Gesetzgebung vorbereitete, den stellvertretenden Vorsitz übernehmen sollte. ${ }^{21}$ Die Ernennungsurkunde für Frank wurde noch am selben Tage von Hindenburg, Hitler und Gürtner unterschrieben.

Schwebte Gürtner vor, daß der Reichsjustizkommissar an sein Ministerium gebunden und ihm unterstellt sein sollte, so hatte Frank offensichtlich andere Vorstellungen. Wie Frank sein Aufgabengebiet anfangs beschrieb, schien es, als wolle er die gesamte Tätigkeit des Reichsjustizministeriums kontrollieren: er nahm nichts weniger als „die Überwachung der gesamten Länder- und Reichsjustiz, des Funktionierens der Rechtsorgane auf allen Gebieten, der Fragen der Justizverwaltung, der Rechtspflege und der Reformen des deutschen Justizwesens" ${ }^{\text {"22 }}$ für sich in Anspruch. Aber anders als auf dem Gebiet der Gesetzgebungsarbeiten, bei deren Leitung Frank Gürtner gegenüber auf „völliger Gleichberechtigung“ bestand ${ }^{23}$, räumte Frank die Gleichschaltung der Justizverwaltung - wie er in seinen in Nürnberg geschriebenen Memoiren bekannte mit der Zeit „zweckmäßigerweise gern Dr. Gürtner ein, weil sich diese ,Verreichlichung' der Länderjustizverwaltungen ausschließlich als auf dem Ministerialgebiet liegend erwies"24: „Ich überließ also Gürtner nach einem gemeinsam von uns beschlossenen Justiznotplan' die absolute Führung der Reichsjustiz und führte den Rechtskampf in meinen anderen, beweglicheren Einrichtungen. ${ }^{25}$ Offensichtlich hegte Frank die Hoffnung, von Hitler sowieso einmal anstelle des Nicht-Nationalsozialisten Gürtner an die Spitze der vereinheitlichten Justizverwaltung gestellt zu werden. Franks Ernennung zum Reichsjustizkommissar und die Handhabung der ihm übertragenen Befugnisse war ein typisches Beispiel für die Praxis Hitlers, neben den normalen staatlichen Ressorts Bevollmächtigte mit unklar umrissenen Vollmachten einzusetzen, deren konkrete Ausgestaltung von den Neigungen, dem politischen Einfluß und der Fähigkeit des Betreffenden abhing, sich gegenüber dem bestehenden Apparat und rivalisierenden Instanzen durchzusetzen. Es ist sehr wahrscheinlich, daß Hitler Frank in diesem Sinne auch ermutigte. ${ }^{26}$

Auf dem staatlichen Sektor strebte Frank - der seit März 1933 auch das Amt des bayerischen Justizministers innehatte - danach, die neuen nationalsozialistischen Landesjustizchefs unter seiner Führung als Gegengewicht zum Reichsjustizministerium zu organisieren, um bei der Reichszentrale bestimmte gesetzgeberische Forderungen durchzusetzen. Am 22. April lud er die Landesjustizminister zu einer Konferenz nach München ein, um zu beraten, wie die Auswirkung der beiden am 7. April erlassenen

21 Niederschrift über die Sitzung des Reichskabinetts am 22.4.1933, vormittags (Akten der Reichskanzlei. Die Regierung Hitler. Teil I, Bd. 1 [s. Kapitel I, Anm. 3], Dok. Nr. 103, S. 360 ff., und BA, Sign. R/43 I/1461).

22 So Frank in einem Interview für den VB, Südd. Ausgabe v. 10.9.1933, S. 1. Die damals allgemein verbreitete Ansicht, daß Frank auch mit der Verreichlichung der Justizverwaltung betraut sei, geht z. B. auch aus der Botschaft der Referendare im BNSDJ an Frank v. 3.10.1933 hervor (s. VB v. 4.10.1933, S.2).

23 Telegr. Franks an Gürtner v. 27.11.1933 (Akten des RJM, BA, Sign. R 22/4723), vgl. dazu Kapitel VII.2.a., S.754 ff.

24 H. Frank, Im Angesicht des Galgens, München-Gräfelfing 1953, S. 162.

25 A.a.O., S. 158.

${ }^{26}$ Über die Unterredung mit Hitler vor seiner Ernennung zum Reichsjustizkommissar berichtete Frank später (a.a.O., S. 156), dieser habe zu ihm gesagt: „,Ich begrüße diese Ihre Berufung sehr. Sorgen Sie dafür, daß endlich der Staub der alten vergilbten Aktenwelt in der Justiz 'gestöbert, wird‘... Ich machte ihn aber darauf aufmerksam, daß meine Vollmachten doch eigentlich nicht in dieser Richtung lauteten, auch zeitlich befristet wären. Da sagte er denkbar heiter: ,Vollmachten sind doch nur ein Sprungbrett. Sie sind nur die Vorstufe zum nächsten Schritt. Beachten Sie meinen Weg!' Ich bat ihn um seine Unterstützung, die er zusagte.“ 
Reichsgesetze über das Berufsbeamtentum und über die Zulassung zur Rechtsanwaltschaft - die ohne Mitwirkung der Landesjustizchefs zustandegekommen waren und ihren antijüdischen Zielsetzungen bei weitem nicht entsprachen - durch radikale Auslegung und Durchführung verschärft werden könnte. Allerdings gelang es Frank nicht, die Führung der Landesjustizminister allein zu übernehmen: auf der Konferenz wurde vielmehr ein ständiger Ausschuß gegründet, dem außer Frank noch Kerrl sowie der kommissarische sächsische Justizminister Thierack angehörten und der die Gesamtheit der Landesjustizminister gegenüber dem Reichsjustizministerium und anderen Reichsbehörden vertreten sollte. Diesem Ausschuß wurde von der Konferenz ein von Kerrl vorgeschlagener Antrag auf Verschärfung der Strafbestimmungen für bestimmte „volksschädigende Korruptionsfälle“27 sowie ein Antrag auf ein erleichtertes Verfahren bei der Aufhebung der Abgeordnetenimmunität übergeben, um beim Reichsjustizministerium eine reichsgesetzliche Regelung zu erreichen. ${ }^{28}$ In der Folge sollte jedoch der Dreierausschuß, der durch die sich verstärkende Rivalität zwischen Frank und Kerrl zusehends gelähmt wurde, keinen Einfluß auf die Reichsgesetzgebung gewinnen; nach der eindeutigen Betrauung des Reichsjustizministeriums mit der einheitlichen Ordnung der Justizangelegenheiten durch Hitler sollten seine drei Mitglieder im Rahmen der Verreichlichung der Justiz andere Funktionen erhalten.

Während des Jahres 1933, in dem sich die Verreichlichung der Justizverwaltung noch im Stadium der Überlegungen befand, konnte das Reichsjustizministerium die Nachteile einer geteilten Justizhoheit zunächst nur durch engere Fühlungnahme mit den Landesjustizverwaltungen ausgleichen. Gürtner beschloß daher, sich an den Konferenzen der Landesjustizminister zu beteiligen. Auf der nächsten dieser Konferenzen, die am 6. Mai in Stuttgart stattfand, wurden im Anschluß an programmatische Reden Franks und Gürtners über die kommende Rechtserneuerung und die Angleichung der Justizverwaltung und Rechtsprechung in den Ländern praktische Themen wie der gleichmäßige Vollzug des Berufsbeamtengesetzes und des Rechtsanwaltsgesetzes vom 7. April besprochen. Hier zeigte sich, daß Frank als Reichsjustizkommissar nunmehr für die strikte Ausführung der Reichsgesetze eintrat und sich als einzige Instanz ansah, die künftig den Willen der nationalsozialistischen Landesjustizchefs bei der Reichsgesetzgebung zu vertreten hatte: die ausbrechende Rivalität zwischen ihm und Kerrl um die Einflußnahme auf die Reichsjustiz machte die in München beschlossene „Fronde“ der Landesjustizminister unmöglich. Auf der Stuttgarter Konferenz wurden ferner die Vereinheitlichung des Strafvollzugs, des Notariatswesens, der Gebührenordnung, der Zulassung und Freizügigkeit von Rechtsanwälten und der Referendarausbildung behandelt und für diese Aufgabengebiete Arbeitspläne festgelegt. ${ }^{29} \mathrm{Am} 2$. und 3. August folgte eine Konferenz der Landesjustizminister im Reichsjustizministerium unter

${ }^{27}$ Vgl. dazu Kapitel VII.3.a., S.834 ff.

${ }^{28} \mathrm{Zu}$ dieser Tagung vgl. Niederschr. über die Konferenz der Justizminister der Deutschen Länder am 22. April $1933 \mathrm{im}$ Bayerischen Staatsministerium der Justiz (Akten des bayer. JM, BayerHStArch. Abt. I, Sign. MJu 16833), ferner VB, Südd. Ausgabe, v. 25.4.33, S.2, und v. 27.4.33, S.1, vor allem auch Kapitel III.1.a., S. $141 \mathrm{ff}$.

29 Vgl. Niederschr. über die Zusammenkunft der Reichs- und Landesjustizminister in Stuttgart am 6. Mai 1933 (Akten des bayer. JM, a.a.O.), ferner VB, Südd. Ausgabe, v. 11.5.33, S.3; dazu Kapitel III.1.a., S. 145 ff, und Kapitel VII.3.a., S.835f. 
Vorsitz von Staatssekretär Schlegelberger, auf der der Entwurf eines Reichsgesetzes zur Sicherung des Rechtsfriedens beraten wurde, der von der preußischen Staatsregierung vorgelegt worden war. ${ }^{30}$

\section{Gürtners „Verreichlichungsplan“: das erste Überleitungsgesetz und die Tagung der Chefs der Landesjustizverwaltungen in Dresden im Februar 1934}

Die staatsrechtliche Voraussetzung für den Aufbau einer reichseinheitlichen Justizverwaltung brachte erst das Gesetz über den Neuaufbau des Reichs vom 30. Januar 1934르, das Deutschland vom Bundesstaat zum Einheitsstaat machte und die Hoheitsrechte der Länder auf das Reich übertrug. Damit wurde das Reich auch alleiniger Träger der Justizhoheit. Da die gesetzgeberischen und organisatorischen Maßnahmen für den Aufbau einer einheitlichen Verwaltung im Reich - eine Aufgabe, vor die sich die meisten Reichsressorts für ihren Geschäftsbereich nunmehr gestellt sahen - unter Umständen Jahre in Anspruch nehmen konnte ${ }^{2}$, verfügte Reichsminister des Innern Dr. Frick durch die 1. Verordnung zum Neuaufbaugesetz, daß die Wahrnehmung der auf das Reich übergegangenen Hoheitsrechte für die erforderliche Übergangszeit „den Landesbehörden zur Ausübung im Auftrage und im Namen des Reichs“ übertragen wurde, soweit „das Reich nicht allgemein oder im Einzelfalle von diesen Rechten Gebrauch macht". Länderverträge und Verwaltungsabkommen blieben in Kraft, neue konnten jedoch nicht mehr abgeschlossen werden. Landesgesetze bedurften der $\mathrm{Zu}$ stimmung des zuständigen Reichsministers, der auch anordnen konnte, daß ihm Rechtsverordnungen vor Erlaß vorgelegt wurden; die obersten Landesbehörden mußten seinen Anordnungen künftig Folge leisten. ${ }^{3}$ Somit wurde auch die Rechtspflege zunächst von den Ländern als Auftragsverwaltung im bisherigen Umfang und nach den geltenden Gesetzen und Verwaltungsvorschriften weitergeführt, wenngleich nunmehr die Landesjustizminister dem Reichsjustizminister unmittelbar unterstellt waren. In einem Erlaß an die Landesjustizverwaltungen vom 6. Februar 1934 wies Gürtner darauf hin, daß eine "einheitliche Reichsjustiz" erst noch geschaffen werden müsse:

„Ihr das Haus zu bauen, in dem sie hinfort heimisch sein soll, ist Aufgabe der nächsten Zeit. Für diese Aufgabe ist das Reichsjustizministerium gerüstet. Bei seiner Arbeit wird es sich auf die reichen Erfahrungen der Landesjustizverwaltungen stützen. Die Schwierigkeiten, die die Vereinheitlichung der Justizverwaltung bietet, dürfen nicht unterschätzt werden. Leitender Gesichtspunkt wird und muß bleiben, die Justiz vor jeder Erschütterung zu bewahren. Erst wenn das Reichsjustizministerium das einheitliche Justizverwaltungsrecht geschaffen und, soweit notwendig, eine weitere Vereinheitlichung des materiellen Rechts vorgenommen haben wird, kann das neue Haus bezogen werden."

30 Vgl. Ber. des GStA Hamburg v. 3.8.33 über die Konferenz (Akten des OLG Hamburg, StArch. Hamburg, Best. 213-1), ferner VB, Südd. Ausgabe, v. 3. und 4. 8.33, Beiblatt, Ủazu Kanitel VII.3a., S. 831 f.

1 RGBI.I, S.75.

2 Vgl. Rundfunkrede des Reichsministers des Innern Frick v. 31.1.1934 (VB, Südd. Ausgabe v. 2. 2. 1934).

${ }^{3}$ Erste VO über den Neuaufbau des Reichs v. 2.2.1934 (RGBl. I, S.81). 
Um die Furcht vor einem gleichmacherischen Zentralismus zu zerstreuen, führte Gürtner ferner aus, daß „die Tradition, die sich in den Landesjustizverwaltungen und in der Rechtspflege der Länder verkörpert", mit der Verreichlichung keineswegs ein Ende finden solle; sie werde vielmehr ,in dem gemeinsamen Ganzen fortgesetzt werden". 4

War zu diesem Zeitpunkt die Zuständigkeit des Reichsjustizministeriums für die Verreichlichung der Rechtspflege gegenüber dem Reichsjustizkommissar bereits abgegrenzt ${ }^{5}$, so stand eine solche Klärung gegenüber dem Reichsministerium des Innern zumindest offiziell noch aus. Frick war durch Artikel 5 des Neuaufbaugesetzes ermächtigt worden, „die zur Durchführung des Gesetzes erforderlichen Rechtsverordnungen und Verwaltungsvorschriften" zu erlassen, und damit zum eigentlichen „Reichsreformminister“ geworden. Bereits durch die 1. Verordnung zum Neuaufbaugesetz hatte er Einfluß auf die Justizhoheit genommen, indem er deren Wahrnehmung den Landesjustizbehörden als Auftragsverwaltung übertrug. An sich hätte nichts im Wege gestanden, daß er auch weiterhin die erforderlichen Maßnahmen zur Reichsreform auf dem Justizgebiet traf. ${ }^{6}$ Aber abgesehen davon, daß alle spezielleren Maßnahmen technisch sowieso vom Reichsjustizministerium hätten vorbereitet werden müssen, scheint die Zuständigkeit zum Aufbau einer reichseinheitlichen Justizverwaltung zwischen den beiden Ministerien des Innern und der Justiz von Anfang an nicht strittig gewesen zu sein: Schon am 5. Februar 1934 leitete Gürtner der Reichskanzlei den Entwurf eines „Ersten Gesetzes zur Überleitung der Rechtspflege auf das Reich“ zu, durch das die Reichsreform auf dem Gebiet der Justiz von dem der Verwaltung abgetrennt wurde. Laut Artikel 5 dieses Entwurfs sollte der Reichsjustizminister ermächtigt sein, „alle Bestimmungen zu treffen, die durch den Übergang der Justizhoheit auf das Reich erforderlich werden“, und damit für sein Ressort die gleichen Befugnisse erhalten, wie sie der Reichsinnenminister für alle allgemeinen Maßnahmen des Reichsneubaus besaß. Neben dieser Klärung der Zuständigkeitsfrage beschränkte sich das Gesetz auf die Regelung einiger grundsätzlicher Materien, die keinen Aufschub vertrugen. So sollte die Einheitlichkeit der Rechtspflege im Reich sofort ihren sichtbaren Ausdruck darin finden, daß alle Gerichte - ob ordentliche, besondere oder Verwaltungsgerichte, ob unmittelbare Gerichte des Reichs, solche der vorläufig im Auftrag des Reichs handelnden Länder oder solche, die bei den Gemeinden bestellt waren nur noch „im Namen des Deutschen Volkes“ Recht sprechen soliten (Art. 1). Das Begnadigungsrecht sollte auch in bisherigen Landessachen dem Reichspräsidenten übertragen werden, der ferner das Recht erhalten sollte, anhängige Strafsachen niederzuschlagen, wozu es bisher auf Reichsebene eines Gesetzes bedurfte. In den einzelnen Ländern war die Niederschlagung bis dahin teils ausdrücklich ausgeschlossen, teils war sie dem Landesgesetzgeber vorbehalten, teils stand sie Regierungsorganen beschränkt oder unbeschränkt zu. Die Ausübung des Niederschlagungsrechts - dessen Regelung

4 Meldung des Deutschen Nachrichtenbüros (DNB) Nr. 304 vom 9.2.1934; auch DJ 1934, S. 173.

${ }^{5}$ Franks Vorstöße, auf diesem Gebiet Zuständigkeiten an sich zu reißen, konnten von Gürtner stets erfolgreich pariert werden. So forderte Frank am 19.9.1934, ihm das im RJM angeblich mit der Aufgabe der Verreichlichung betraute, neu errichtete „Referat R“ zu unterstellen. Gürtner konnte jedoch Franks falsche Meinung berichtigen, daß hier eine mit zentralen Befugnissen ausgestattete Stelle eingerichtet worden sei: lediglich um die aus Aniaß der Verreichlichung entstehenden Schriftstücke bürotechnisch zusammenzuhalten, sei für sie die einheitliche Geschäftsbezeichnung „R“ eingeführt worden (Akten des RJM, BA, Sign. R 22/4723).

6 Vgl. dazu B. Dennewitz, Einheitsstaat und Reichsverwaltung (RVerwBl. 1935, S. 4 ff.). 
wegen zunehmender Verstöße von Nationalsozialisten gegen die Strafgesetze bei der Verfolgung politischer Gegner ein brennendes Problem geworden war ${ }^{7}$ - sollte der Reichspräsident in gleicher Weise wie bisher schon das Begnadigungsrecht weiterübertragen können (Art. 2). Ferner sollte der Anwaltschaft die volle Freizügigkeit im ganzen Reichsgebiet gewährt werden: wer die Befähigung zum Richteramt besaß, sollte künftig nach Maßgabe der reichsgesetzlichen Vorschriften in jedem Lande zur Rechtsanwaltschaft zugelassen werden, nicht mehr nur in dem Land, in dem er die zweite Staatsprüfung bestanden hatte (Art. 3). Auch den notariellen Urkunden sollte eine solche Freizügigkeit gesichert werden; sie sollten im ganzen Reichsgebiet gelten und entgegenstehende landesrechtliche Vorschriften außer Kraft treten (Art. 4). ${ }^{8}$

In seinem Begleitschreiben vom 5. Februar 1934 bat Gürtner den Staatssekretär in der Reichskanzlei Lammers, über den Gesetzentwurf baldigst einen Beschluß des Reichskabinetts herbeizuführen oder - falls für die nächsten Tage keine Kabinettssitzung vorgesehen sei - wegen der „Eilbedürftigkeit“ eine Genehmigung im Umlaufwege zu erreichen. Daraufhin wurde der Entwurf von Lammers bereits am nächsten Tage den übrigen Reichsministern als Kabinettsvorlage zugestellt und am 9. Februar auch von Hitler gebilligt. Da bis zur gesetzten Frist am 11. Februar kein Minister Widerspruch eingelegt hatte, konnte Lammers Gürtner schon am nächsten Tag mitteilen, daß das Gesetz von der Reichsregierung genehmigt sei.' Es wurde von Hitler, Gürtner, Frick sowie von jenen Kabinettsmitgliedern, in deren Geschäftsbereich Gerichte tätig wurden - Reichsfinanzminister Schwerin von Krosigk, Reichswirtschaftsminister Schmitt, Reichsarbeitsminister Seldte und Reichswehrminister von Blomberg - unterzeichnet und mit dem Datum 16. Februar 1934 als Regierungsgesetz im Reichsgesetzblatt verkündet. ${ }^{10}$

Waren mit diesem Gesetz die Zuständigkeit für die Verreichlichung der Justiz eindeutig geregelt und die ersten Maßnahmen für deren Verwirklichung ergriffen worden, so galt es nun, Entscheidungen über das Ziel - d.h. die Struktur der zukünftigen Reichsjustizverwaltung - und über den Weg - d.h. das Verfahren zu seiner Verwirklichung - zu treffen. Für die strukturelle Gestaltung der Justizverwaltung war wesentlich, daß ihr Unterbau, die Organisation der Gerichte, bereits nach Reichsrecht einheitlich geregelt war. Auch die Zuständigkeiten der Gerichte waren im großen und ganzen dieselben; sogar die Bezeichnung der höheren Beamten war einheitlich. Die auf diesem Sektor vorhandenen landesrechtlichen Besonderheiten spielten dabei lediglich eine sekundäre Rolle. Somit handelte es sich im wesentlichen um eine Neuordnung auf der Ebene der Zentralinstanz. Der Gedanke, zwischen dem Ministerium und den nachgeordneten Behörden nochmals besondere Verwaltungsdienststellen - eine Art von Unterministerien - für Länder- oder Provinzgruppen einzuschieben, wurde abgelehnt: sie hätten die Einheitlichkeit z. B. der Leitung der Staatsanwaltschaft oder der Personalpolitik erneut gefährdet und die Nachteile des bisherigen Zustandes in gewissem Umfang aufrechterhalten. Für die Justizverwaltung kam daher nur eine einzige Zentralinstanz in Frage, die alle Justizbehörden als unmittelbare Reichsbehörden unter eine Gesetzgebung und eine Leitung vereinte. Was lag näher, als diese Zen-

\footnotetext{
7 Vgl. dazu Kapitel IV.

8 Entw. des G. mit Begründung in den Akten der ehemaligen Reichskanzlei (BA, Sign. R 43 II/1505).

9 Vgl. die Korrespondenz über das G., a.a.O.

10 RGBI. I, S. 91.
} 
tralinstanz durch eine Erweiterung des Reichsjustizministeriums zu gewinnen, das bereits den überwiegenden Teil der Gesetzgebung, die Verwaltung des Reichsgerichts und des Reichspatentamtes innehatte? Zu diesem Zweck mußten die sechzehn obersten Landesjustizbehörden ${ }^{11}$ aufgelöst und ihre Verwaltungsaufgaben sowie im notwendigen Umfang ihr Personal vom Reichsjustizministerium übernommen werden. Neben dieser Aufgabe mußten die Justizbehörden in den Ländern dem bereits bestehenden allgemeinen Behördenrecht des Reichs unterstellt und dazu auf dem Gebiet der Justiz eigene einheitliche Bestimmungen - ein Reichsjustizverwaltungsrecht - geschaffen werden, ohne das eine gedeihliche Zusammenarbeit kaum möglich war. Gürtner entschloß sich, noch vor dem Ausbau des Reichsjustizministeriums zur alleinigen Zentralinstanz mit den Arbeiten an einem solchen einheitlichen Justizverwaltungsrecht zu beginnen.

Anfang Februar 1934 unternahm der preußische Justizminister Kerrl einen Vorstoß, der diese Pläne Gürtners zu durchkreuzen drohte. Seine Absicht war, die Verreichlichung an sich zu reißen und sich - zum Nachteil seines Rivalen, des Reichsjustizkommissars - eine bessere Ausgangsposition für eine eventuelle Übernahme der Justizverwaltung im ganzen Reich zu schaffen. In einer Unterredung mit Gürtner am 2. Februar erhob er "den Anspruch darauf, die Justizverwaltung in Nord- und Mitteldeutschland von sich aus zu vereinheitlichen mit dem Bemerken, daß der Anschluß des Südens der weiteren Entwicklung vorbehalten bleiben könne“. Gürtner mußte diesen Schritt, der lediglich eine „Verpreußung“ anderer Landesjustizverwaltungen bedeutet hätte, schon aus dem Grunde ablehnen, weil er statt des Reichsjustizministeriums das preußische Justizministerium zur eigentlichen Zentralinstanz für die Verreichlichung der Justizverwaltung gemacht hätte. Auch sah er wohl die Schwierigkeiten voraus, die bei der weiteren Vereinigung der so geschaffenen Nord- und Südblöcke durch die Rivalität Kerrls und Franks unweigerlich auftreten mußten. In einer mehr als dreistündigen Aussprache gelang es ihm, Kerrl zur Annahme eines Stufenplans zu bewegen, nach dem zunächst die drei Landesjustizminister von Preußen, Sachsen und Bayern jeweils gemeinsam mit den Justizverwaltungen der übrigen nord-, mittel- und süddeutschen Länder Vorschläge für ein künftiges Reichsjustizverwaltungsrecht erarbeiten sollten. Kerrl stimmte schließlich mit der Maßgabe zu, „daß eine Zuständigkeit des Reichsjustizkommissars auf diesem Gebiete nicht bestehe “. ${ }^{12}$ Zwei

1 Die Aufgaben der obersten Landesjustizbehörden nahmen wahr in Preußen: der Justizminister,

in Bayern: das Staatsministerium der Justiz,

in Sachsen: das Ministerium der Justiz,

in Württemberg: das Justizministerium,

in Baden: das Ministerium des Kultus, des Unterrichts und der Justiz, Abteilung Justiz,

in Thüringen: der Justizminister,

in Hessen: das Staatsministerium, Ministerialabteilung Ic (Justiz),

in Hamburg: die Landesjustizverwaltung,

in Mecklenburg: das Justizministerium,

in Braunschweig: der Justizminister,

in Oldenburg: das Ministerium der Justiz,

in Anhalt: das Staatsministerium,

in Bremen: der Senat der Freien Hansestadt Bremen,

in Lippe: die Landesregierung,

in Lübeck: der Senat der Freien und Hansestadt Lübeck,

in Schaumburg-Lippe: die Landesregierung.

12 Vgl. Verm. v. 5.2.34 über die Bespr. (Akten des RJM, BA, Sign. R 22/4723). 
Tage später befürwortete auch der sächsische Justizminister Thierack den Plan Gürtners und schlug die baldige Einberufung einer Konferenz der Landesjustizminister in Dresden vor. Am 5. Februar 1934 - am gleichen Tage, an dem er der Reichskanzlei seinen Entwurf des Ersten Überleitungsgesetzes zustellte - lud Gürtner die Chefs der Landesjustizverwaltungen für den 12. Februar zu einer grundlegenden Tagung nach Dresden ein, um ihnen seinen Verreichlichungsplan zu unterbreiten. ${ }^{13}$ Trotz der Wahl dieses ,neutralen “ Konferenzortes blieb Frank der Tagung fern. ${ }^{14}$

Auf dieser Sitzung, die im Sächsischen Gesamtministerium am Königsufer stattfand und durch eine Begrüßungsansprache Thieracks eröffnet wurde, gab Gürtner den versammelten Landesjustizministern oder deren Vertretern den Wortlaut des Ersten Überleitungsgesetzes bekannt, dessen Billigung durch das Reichskabinett er soeben aus Berlin erfahren hatte. Er wies anschließend darauf hin, daß der Aufbau einer Reichsverwaltung bei der Justiz durch den bereits vorhandenen einheitlichen Unterbau einfacher sei als bei anderen Ressorts, wo die Verhältnisse organisatorisch und rechtlich bei weitem komplizierter lägen. Ferner habe die territoriale Gliederung der aufzubauenden Justizverwaltung nichts mit der viel erörterten und weit schwierigeren Frage der territorialen Neuordnung Deutschlands zu tun: hier handele es sich lediglich um eine Einteilung des Reiches in Oberlandesgerichtsbezirke, und zwar zunächst in ihrer gegenwärtigen Form. Eine Neuordnung der in der Größe sehr unterschiedlichen Oberlandesgerichtsbezirke sowie ihre räumliche Anpassung an die Gau-, Verwaltungs-, Finanz- und Wehrbezirke sei eine spätere Aufgabe, die im Laufe der Zeit gelöst werden könne. Auch die Frage, ob zwischen dem Reichsjustizministerium und den Oberlandesgerichtspräsidenten - denen künftig auf dem Gebiet der Justizverwaltung Aufgaben übertragen würden - noch eine Zwischeninstanz, etwa ein Statthalter oder ein Gauleiter mit gewissen Hoheitsrechten, eingeschaltet werden solle ${ }^{15}$, könne gegenwärtig außer acht bleiben. Er beabsichtige auch nicht, bereits auf dieser Tagung bestimmte Regelungen für eine einheitliche Justizverwaltung vorzuschlagen; vielmehr wolle er einen Überblick über die zu lösenden Fragen geben, und zwar unter den beiden Gesichtspunkten, was zu geschehen habe und wie es zu geschehen habe.

Die Verreichlichung der Justizverwaltung werde sich auf zwei großen Sachgebieten auswirken: bei der Gesetzgebung und bei der Verwaltung im engeren Sinne. Bei der Gesetzgebung handele es sich einmal um eine Angleichung der Ausführungsgesetze zur Reichsgesetzgebung, von denen gegenwärtig kaum zwei übereinstimmten, ferner der zahlreichen landeseigenen Gesetze, die besondere Verhältnisse in den jeweiligen Ländern regelten und die Justizverwaltung berührten. Gürtner zählte anschließend eine Reihe landesrechtlicher Besonderheiten auf den verschiedensten Rechtsgebieten auf, die durch ein einheitliches Recht beseitigt werden müßten. Diese Aufgaben der Gesetzesangleichung seien jedoch „zeitlich nicht die vordringlichsten“. Hier könnten

13 Einladung, Programm der Dresdener Tagung und die vom Staatsanwalt im Sächsischen Justizministerium Klemm gefertigte Verhandlungsniederschr. sowie ein zusammenfassender Ber. Präs. Struves als Vertreter des Justizsenators Rothenberger in der Hamburger Landesjustizverwaltung (Akten des OLG Hamburg, StArch. Hamburg, Best. 213-1). Der VB, Südd. Ausgabe, v. 2.2.1934, S.2, verbreitete die Meldung, daß die Einberufung dieser Tagung auf Veranlassung Franks erfolge, „der auch die Besprechung leiten wird“.

14 Außer mit Kerrl hatte sich Frank in dieser Zeit - wegen der Zuständigkeit für die Strafrechtsreform - auch mit Gürtner überworfen. Vgl. Kapitel VII.2.a., S.754 ff.

15 Die Bemerkung zeigt die damals noch ungeklärte Stellung der Reichsstatthalter (Gauleiter) im künftigen Staatsaufbau. 
die Landesjustizverwaltungen selbst schon jetzt prüfen, was angeglichen werden könne und was auch in einem künftigen Reichsrecht erhalten bleiben müsse. Der weitaus größere und dringlichere Teil der Aufgaben liege vielmehr auf dem Gebiet der reinen Justizverwaltung, die es einmal mit Menschen und zum anderen mit Sachen zu tun habe. Soweit sich die Justizverwaltung mit Menschen befasse, müßten künftig folgende Sachgebiete vereinheitlicht werden: vor allem die Personalverwaltung, dann das Begnadigungsrecht - wobei die Ausübung dieses Rechts nach unten, „etwa an die Oberlandesgerichtspräsidenten oder Generalstaatsanwälte“, delegiert werden müsse. Überhaupt gelte als oberster Grundsatz: „Was nicht an die Spitze gezogen werden muß, um überhaupt die Einheitlichkeit zu gewährleisten, das muß nach unten dezentralisiert werden." Weitere Sachgebiete, auf denen einheitliche Regelungen erfolgen müßten, seien die Besoldungsordnung, das Notariats- und Rechtsanwaltswesen, die Laufbahn für höhere, mittlere und untere Beamte, das Ausbildungs- und Prüfungswesen, die Grundsätze bei der Anstellung der Justizbeamten - vor allem, um eine Austauschmöglichkeit der Beamten im gesamten Reichsgebiet zu erreichen -, das Disziplinarrecht für Richter sowie die Regelung des inneren Dienstbetriebes. Von jenen Bereichen der Justizverwaltung, die sich auf Sachen bezögen, seien folgende dringend zu vereinheitlichen: das Haushaltswesen, bei dem die unbedingt erforderliche Vergleichbarkeit des Etats und Betriebsaufwands von Gerichten verschiedener Länder bisher fehle, das Kassenwesen, das Gebührenwesen, die Rechnungslegung und -kontrolle, die Geldbeschaffung, das Bauwesen, in dem bei verschiedenen Ländern eine komplizierte Instanzenhäufung herrsche, die in der künftigen Reichsverwaltung vermieden werden müsse, das Kraftfahrwesen, der Strafvollzug, bei dem bereits eine starke materielle Annäherung erreicht worden sei, und das Gerichtsvollzieherwesen. Nach diesem „flüchtigen und gar nicht erschöpfenden Überblick über das Gelände, das überhaupt zu beackern ist“, wandte sich Gürtner der Frage zu, in welcher zeitlichen Reihenfolge alle diese Aufgaben erfüllt werden sollten, und stellte den Grundsatz auf, daß diejenigen Aufgaben am dringlichsten seien, die eine lange Anlaufzeit bis zu ihrer Auswirkung benötigten, wie z.B. das Ausbildungs- und Prüfungswesen. Wichtig sei vor allem, daß die Länder von sich aus auf eine Angleichung bedacht seien und in dieser Hinsicht bereits soviel in die Praxis umsetzten, wie ohne innere Störungen möglich sei.

Anschließend ging der Minister zur Frage über, welcher Weg bei der Vereinheitlichung der Justizverwaltung einzuschlagen sei, damit „alles das, was hier an Erfahrungen und Gedankengut im Deutschen Reiche lebt, auch nutzbar gemacht werden kann“. Es sei der Wunsch Hitlers, daß für diese Aufgabe kein besonderer Apparat an der Zentrale geschaffen werden solle. Ebensowenig sollten dafür aus allen Teilen des Reichs Sachverständige zusammengeholt werden, um „gewissermaßen von oben her nun das Dach über die Justizverwaltung“ zu bauen; vielmehr solle „diese Arbeit nur von unten her geleistet werden“. Drei verschiedene Möglichkeiten seien erwogen und wieder verworfen worden:

Als erste Möglichkeit sei erörtert worden, „den Staat als Vorbild zu nehmen, der drei Fünftel des Reiches umfaßt“, d.h. das preußische System „nach Prüfung, Besserung und Veredelung auf das Reich zu übernehmen“. Der Haupteinwand gegen dieses Verfahren käme nicht einmal so sehr von der Verwaltungstechnik her, sondern sei vielmehr ein politisch-psychologischer. Auf die Einstellung seiner bayerischen Lands- 
leute gegenüber Preußen anspielend, führte Gürtner in humoristischer Weise aus: "Ich verzichte darauf, das im einzelnen auszumalen oder Ihnen etwa gar in der Sprache meiner Heimat darzustellen (Heiterkeit), wie man ein solches Verfahren kritisieren würde."

Die zweite Möglichkeit wäre gewesen, die bestehenden sechzehn Landesjustizverwaltungen zu einem Arbeitskollegium für die Ausarbeitung des neuen deutschen Justizverwaltungsrechts zusammenzufassen. Ein solches Verfahren hätte aber ungewöhnlich viel Zeit in Anspruch genommen und am Schluß sicher zu keiner auch nur halbwegs befriedigenden Lösung geführt. „Der Kanzler“, berichtete Gürtner, „mit dem ich gesprächsweise alle diese Gedanken durchgegangen habe, hat sich von der Vorstellung eines von 16 Justizverwaltungen beschickten Gremiums mit Schaudern abgewendet und erklärt, von allem, was ich sagen würde, wäre das ganz gewiß das am wenigsten Mögliche."

Die dritte Möglichkeit hätte in der Bildung eines Arbeitskollegiums aus den drei größten Justizverwaltungen - der preußischen, der bayerischen und der sächsischen bestanden, dem die Aufgabe hätte übertragen werden können, die bestehenden landesrechtlichen Bestimmungen auf dem Gebiet der Justizverwaltung zu sammeln, kritisch zu sichten und daraus Vorschläge für eine Übernahme als Reichsrecht zu machen: um eine solche Sammlung handele es sich zunächst, da es in Deutschland einschließlich der hier Anwesenden keinen Menschen gebe, der auch nur auf einem Gebiet den bestehenden Rechtszustand kenne. Diese Methode eines Dreier-Kollegiums hätte aber den Nachteil gehabt, daß neben den drei Ländern „das übrige Deutschland als Objekt und nicht als Subjekt dieser Arbeit" betrachtet werde und die nicht beteiligten dreizehn Justizverwaltungen ,in das peinliche Gefühl versetzt werden, als ob sie nicht mehr da wären“. Eine weitere Folge wäre gewesen, „daß man ausgezeichnete Gedanken, die im kleinsten Landesgebiet mit Erfolg ausgeführt worden sind, gar nicht zu beachten in die Lage käme“.

Um diese Gefahr auszuschalten, habe er Hitler eine vierte Lösung vorgeschlagen, der dieser "ohne jede Debatte und ohne Widerspruch seine Zustimmung gegeben“ habe: Die sechzehn Justizverwaltungen sollten zu drei Arbeitsgemeinschaften zusammengefaßt werden, die sich unter der Federführung der drei großen Justizverwaltungen von Preußen, Bayern und Sachsen einen Überblick über das in den Ländern geltende Justizverwaltungsrecht verschaffen und dieses Material unter dem Gesichtspunkt prüfen sollten, was davon in einem künftigen Reichsjustizverwaltungsrecht erhalten bleiben und was yon vornherein ausgeschieden werden solle. Aus dieser Materialsammlung und den gegebenen Empfehlungen werde dann das Reichsjustizministerium seinerseits Vorschläge erarbeiten. Die drei Ländergruppen sollten wie folgt zusammengesetzt werden: die süddeutsche aus den Ländern Bayern, Württemberg und Baden, die mitteldeutsche aus Sachsen, Thüringen und Hessen und die norddeutsche aus Preußen und den übrigen in seinem geographischen Bereich liegenden Länder bzw. Hansestädte. Für die beabsichtigte Gruppenbildung seien, wie auch Hitler ausdrücklich betont habe, keine politischen, sondern lediglich räumlich-technische $\mathrm{Ge}$ sichtspunkte maßgebend gewesen. Daß innerhalb der drei Gruppen auf manchen Gebieten der Justizverwaltung recht unterschiedliche Systeme bestünden, sei dabei kein Nachteil, sondern biete im Gegenteil die Gewähr dafür, daß alle Systeme auch eingehend diskutiert würden. 
Nach Gürtner sprach Kerrl. Er begrüße, daß die nationalsozialistische Reichsreform aufgrund des Neuaufbaugesetzes vom 30. Januar 1934 - von dem selbst er als Vizepräsident des Reichstages völlig überrascht worden sei - jetzt auf dem Gebiet der Justiz tatkräftig in Angriff genommen werde. Einen Tag nachdem das erwähnte Gesetz vom Reichstag beschlossen worden sei, habe er den Reichsjustizminister um eine Unterredung gebeten, und „schon nach einer halben Stunde“ seien sie sich darüber einig gewesen, daß vor einer Auflösung der Landesjustizministerien zunächst die Verwaltungstechnik in den Ländern vereinheitlicht werden müsse:

„Wollte ich dem Herrn Reichsjustizminister mein Preußisches Justizministerium übergeben, so müßte er mir notgedrungen sagen: Bleiben Sie mir damit vom Halse, soweit sind wir noch nicht, denn außer dem preußischen müßte ich ja auch gleichzeitig die Ministerien von Bayern, Thüringen, Sachsen und weiteren 12 Ländern übernehmen. Das geht aber noch nicht, denn vorher müssen die Ministerien in ihrem Aufgabenkreis unbedingt beschränkt werden."

Zunächst müßten die Länderministerien in der Form auseinandergegliedert werden, daß ein Teil ihrer Aufgaben nach unten - „dem Reichsstatthalter bzw. seinem Vertreter in der Justiz“ - abgegeben und der Rest der Reichsjustizverwaltung übertragen werde. Die vom Reichsjustizminister zur Vorbereitung eines einheitlichen Justizverwaltungsrechts vorgeschlagene Gruppeneinteilung halte er für zweckmäßig und auch seitens der Justizminister der kleineren Länder für annehmbar, da sie „lediglich eine technische Maßnahme“ darstelle, die „keinerlei Unterstellung der Justizverwaltung der Länder unter die geschäftsführende Justizverwaltung der Gruppe“ bedeute: in die Verwaltung der einzelnen Länder ihrer Gruppe habe letztere „in keiner Weise hineinzureden“. Die historischen Tatsachen beschönigend, wies er in diesem Zusammenhang darauf hin, daß gerade Preußen die ihm angeschlossenen Landesteile nie „eingepreußt, sondern eingedeutscht“ habe, da Preußen von allen deutschen Staaten stets am stärksten auf die Schaffung einer gemeinsamen höheren Einheit ausgerichtet gewesen sei. Kerrls Hinweis, daß Preußen aufgrund seiner geschichtlichen Erfahrung für die Lösung der bevorstehenden Aufgabe besonders qualifiziert sei, sowie seine Betonung, daß er das preußische Justizministerium vorläufig nicht aus der Hand zu geben gedenke, lagen ganz auf der Linie seiner eigennützigen Ziele, deren Verfolgung er durchaus noch nicht aufgegeben hatte. Am Schluß appellierte Kerrl an die Anwesenden, daß die Justizverwaltung die Verreichlichung schnell und beispielgebend vorantreiben möge, um damit auch den anderen Ressorts zu helfen, für die diese Aufgabe weit schwieriger zu lösen sei.

Als Vertreter des abwesenden bayerischen Justizministers Frank sicherte Ministerialrat Meukel die loyale Mitwirkung der bayerischen Justizverwaltung bei der Verreichlichung zu. Er wolle nicht verhehlen, daß er mit der Besorgnis nach Dresden gekommen sei, es werde eine Übertragung des preußischen Verwaltungs- und Rechtssystems auf sein Land beabsichtigt. Diese Besorgnis habe der Reichsjustizminister durch seine Ausführungen „von Grund aus zerstreut“. Die vorgeschlagene Lösung sei eine „durchaus glückliche“ und er hoffe, daß die übrigen Länder der vorgesehenen Arbeitsgruppe Süd gern mit Bayern zusammenarbeiten werden.

Zum Abschluß ergriff Gürtner noch einmal das Wort und wiederholte, daß es sich bei dem Vorhaben um keine stumpfsinnige Gleichmacherei handele, sondern daß die lebenswerten Eigenarten der deutschen Stämme auch auf diesem Gebiet bewahrt bleiben müßten. Um keinen falschen, Ressentiments weckenden Eindruck von dem Vor- 
haben aufkommen zu lassen, bitte er die Anwesenden, von sich aus über diese Tagung keine Nachrichten an die Presse zu geben, sondern die Behandlung dieser Angelegenheit ihm zu überlassen. Er beabsichtige, nur eine kurze Pressenotiz erscheinen zu las$\operatorname{sen}^{16}$; mit den „einzelnen Fragen, die uns hier die Köpfe heiß machen“, brauche die Öffentlichkeit nicht belastet zu werden.

\section{Die Auseinandersetzung Gürtners mit dem preußischen Ju- stizminister Kerrl um die Kompetenz für die „Verreichlichung“: Vereinigung der Justizministerien des Reichs und Preußens (Mai bis Oktober 1934)}

Hatte Gürtner auf der grundlegenden Tagung in Dresden abermals zum Ausdruck gebracht, daß vor dem Ausbau einer entsprechenden Zentralinstanz zunächst ein einheitliches Justizverwaltungsrecht geschaffen werden müsse, so sollte von unerwarteter Seite ein Anstoß erfolgen, der die Erweiterung des Reichsjustizministeriums zur einzigen Zentrale der Justizverwaltung beschleunigte. In seiner Dresdener Begrüßungsansprache hatte Thierack ausgeführt, daß die Länderjustizminister gern von der Bühne abträten, wenn dafür die langersehnte Justizhoheit des Reichs verwirklicht werde, und hatte in diesem Sinne dem Reichsjustizminister - nichtsahnend, daß er acht Jahre später Gürtners Stellung innehaben werde - zugerufen: „Nicht morituri te salutant, sondern nascituri!" Zwei der führenden nationalsozialistischen Justizbeamten, die auf keinen Fall zu jenen morituri gehören wollten, waren Kerrl und sein Duzfreund Roland Freisler, der im März 1933 als Ministerialdirektor in Kerrls Ministerium berufen und am 1. Juni zu dessen Staatssekretär ernannt worden war. Sie beabsichtigten im Gegenteil, sich durch einen überraschenden Salto auf die Reichsebene hinaufzuschwingen, und zwar durch den Versuch, das preußische Justizministerium durch Hitler zum Reichsjustizministerium erheben und mit der Verreichlichung der Justizverwaltung betrauen zu lassen, während das Ministerium Gürtners in eine andere Rolle abgedrängt werden sollte. Die Verfolgung dieses Plans erschien ihnen um so dringlicher, als sie bei der unterdessen in Gang gekommenen Vereinheitlichung der Justizverwaltung ihre eigenen Vorstellungen gegenüber Gürtner nicht in genügendem Maße durchzusetzen vermochten. Nachdem Kerrl am 15. Mai 1934 über diese Idee mit Staatssekretär Lammers gesprochen hatte, sandte Freisler am folgenden Tag eine Denkschrift an die Reichskanzlei, in der er den Vorschlag begründete. ${ }^{1}$ Freisler wies darauf hin, daß sich seit der Machtergreifung die Aufgaben der Justiz wegen der notwendigen Rechtserneuerung und Neuorganisation sowohl auf dem Gebiet der Gesetzgebung wie auf dem Gebiet der Verwaltung vervielfacht hätten und noch weiter zunähmen. Da alle diese Aufgaben unmöglich gleichzeitig von einer Stelle mit Erfolg gemeistert werden könnten, sei eine „Teilung der Gesamtaufgabe“ geboten. Neben dem Hinweis auf die in England bestehende Zweiteilung der Justizaufgaben zwischen

${ }^{16}$ Vgl. z. B. den Ber. im VB, Südd. Ausgabe, v. 13.2.1934, S. 2.

${ }^{1}$ Vgl. Akten der Reichskanzlei. Die Regierung Hitler. Teil I, Bd. 2 [s. Kapitel I, Anm.3], Dok. Nr.349, S. 1279 ff., und BA, Sign. R 43 II/1505. 
Lordkanzler und Innenminister führte Freisler Beispiele aus der deutschen Geschichte an, bei denen dieser Weg in Zeiten besonderer Aufgabenbelastung auch beschritten worden sei. So habe Preußen von 1817 bis 1820 für die Regelung des Rechtswesens in seinen nach den Befreiungskriegen neugewonnenen Landesteilen neben dem Justizministerium ein eigenes Ministerium für Gesetzesrevision eingerichtet. Eine ähnliche Teilung der Justizaufgaben zwischen einem Justizverwaltungsministerium und einem Gesetzgebungsministerium habe es in Preußen wegen des verstärkten Umfangs gesetzgeberischer Arbeiten nochmals in den Jahren zwischen 1832 und 1848 gegeben. Die Aufgaben, die die deutsche Justiz heute zu bewältigen habe, seien demgegenüber unvergleichlich schwieriger und umfangreicher: Selbst für das größte Land Preußen würde die Übernahme der anderen Länderjustizverwaltungen eine Vermehrung der von der Zentralinstanz zu verwaltenden Amtsgerichte von 946 auf 1646, eine Vermehrung der zu betreuenden Richter von 5734 auf 9943 sowie eine Erhöhung der Zahl der zu überwachenden Rechtsanwälte von 11474 auf 19276 bedeuten. ${ }^{2}$ Die Bewältigung aller Aufgaben durch ein Ministerium würde daher „den Erfolg der Arbeit gefährden“ und die Kräfte eines Ministers bei weitem überfordern: „Die Teilung des künftigen Reichsjustizministeriums ist hiernach eine zwingende Notwendigkeit." Deshalb solle das jetzige Reichsjustizministerium als „Reichsministerium der Gesetzgebung“ seine bisherigen Aufgaben bei der Rechtserneuerung behalten, „das künftige Reichsministerium der Justiz dagegen würde im wesentlichen diejenigen Aufgaben - selbstverständlich für das ganze Reichsgebiet - zu lösen haben, die heute für PreuBen das Pr. Justizministerium erledigt“, und auf diesem Gebiet auch die gegenwärtigen Reformarbeiten übernehmen. Freisler stellte in Aussicht, daß die beiden Reichsministerien wieder vereinigt werden könnten, „wenn die Sonderaufgaben der jetzigen Erneuerungs- und Vereinheitlichungsepoche ... theoretisch gelöst, in Verwaltungsmaßnahmen und Gesetzen niedergelegt und praktisch eingeführt und bewährt" seien, wozu es allerdings ,jahrelanger Arbeit“ bedürfe. Bis dahin hofften Kerrl und Freisler, als Reichsjustizminister bzw. dessen Staatssekretär, offensichtlich fest genug im Sattel zu sitzen, um auch bei einer Wiederzusammenlegung der Ministerien an der Spitze zu bleiben.

Sofort nach Erhalt dieser Denkschrift informierte Lammers Gürtner über deren Inhalt. Bis zum Monatsende kam es zwischen beiden zu mehreren Unterredungen ${ }^{3}$, in denen Gürtner seine Bedenken gegen dieses Vorhaben geltend machte. Die vorgeschlagene Aufgabenteilung mußte die bisher schon als Nachteil empfundene Trennung von Justizgesetzgebung und Justizverwaltung geradezu verewigen. Waren die Arbeiten an der Verreichlichung der Justizverwaltung nach Regelung der Zuständigkeit endlich in Gang gekommen, so schienen sie nun durch den Anspruch der KerrlFreisler-Gruppe im preußischen Justizministerium erneut gefährdet. Aber es schien nur so: nach Vortrag durch Lammers entschied Hitler am 31. Mai 1934, „daß die Schaffung zweier Reichsjustizministerien (für Gesetzgebung und für Verwaltung)

\footnotetext{
2 Diese Zahlen sind offensichtlich dem Statistischen Jahrbuch für das Deutsche Reich, herausgegeben vom Statistischen Reichsamt, 52.Jg. 1933, Berlin 1933, S. 530, entnommen. Der in diesen Zahlenangaben enthaltene Hinweis, daß die preußische Justizverwaltung ohnehin schon den überwiegenden Anteil der Gerichte, Richter und Rechtsanwälte betreue, war hinsichtlich der Absicht der Denkschrift nicht ungeschickt.

3 Vgl. Gürtners Schr. an Lammers v. 25.5.1934 (Akten der RK, BA, Sign. R 43 II/1505).
} 
nicht in Frage kommen könne". ${ }^{4}$ Diese Entscheidung konnte wohl kaum anders ausfallen, nachdem Hitler den Plan zur Vereinheitlichung der Justizverwaltung mit Gürtner eingehend erörtert und diesen ausdrücklich damit beauftragt hatte. Darüber hinaus standen Hitler als gebürtigem Österreicher die süddeutschen Ressentiments gegen eine Durchführung der Verreichlichung durch das preußische Justizministerium klar vor Augen: hatte er doch deshalb die Verreichlichung durch eine bloße „Verlängerung" der preußischen Verwaltung bereits abgelehnt. Dagegen entschied Hitler, daß die Ernennung Kerrls zum Reichsminister ohne Geschäftsbereich, die offenbar Lammers zur Besänftigung Kerrls vorgeschlagen hatte, „erwogen werden“ könne. Gürtner und Kerrl wurden über Hitlers Entscheidung von Lammers sofort telefonisch unterrichtet. Daraufhin kam es noch am Nachmittag jenes 31. Mai zwischen Gürtner und Kerrl in Gegenwart ihrer jeweiligen Staatssekretäre Schlegelberger und Freisler zu einer dramatischen Auseinandersetzung. ${ }^{5}$ Kerrl behauptete, daß er die Übertragung der Reichsjustizverwaltung ,im üblichen Sinne“ nie gefordert habe, er beanspruche jedoch, mit der Verreichlichung der Justiz beauftragt zu werden. Gleichzeitig damit müsse aber das Amt seines nationalsozialistischen Rivalen Frank als Reichsjustizkommissar aufgehoben werden. Auf Gegensätze anspielend, die sich unterdessen zwischen ihm, Gürtner und Frank bei der Schaffung des einheitlichen Reichsjustizverwaltungsrechts aufgetan hatten, betonte Kerrl, er lege den in Dresden dargelegten Verreichlichungsplan dahingehend aus, daß der Reichsjustizminister an einen gemeinschaftlichen Vorschlag durch die Leiter der drei Arbeitsgruppen (Kerrl, Thierack und Frank) hätte gebunden sein sollen. Eine solche Einigung zwischen den drei Landesjustizministern sei jedoch „durch das ständige Versagen des Bayerischen Justizministers Frank unmöglich geworden“. Da er seine eigenen Vorstellungen auf diesem Gebiet nicht hatte durchsetzen können, kündigte Kerrl mit den Worten: „Ich will den Dresdner Plan nicht ausführen, ich sabotiere ihn" seine weitere Mitarbeit auf und lehnte ab, weiter „Untergebener des Reichsjustizministers zu sein“. Auch das Angebot, Reichsminister ohne Geschäftsbereich zu werden, schlage er aus, ,wenn ihm nicht gleichzeitig unter Wegfall des Reichsjustizkommissars die Verreichlichung übertragen werde“. Sollten jedoch seine Bedingungen nicht erfüllt werden, so werde er von seinem Amt als preußischer Justizminister zurücktreten. Diesem Ultimatum ließ er eine handfeste Drohung folgen:

„Er mache darauf aufmerksam, daß sein Ausscheiden aus dem Amte Schwierigkeiten von Parteiseite gegen den Reichsjustizminister zur Folge haben werde; man werde sich in der Partei daran erinnern, daß die Verreichlichung der Justiz eine nationalsozialistische Sache sei.“

Unter diesen Umständen blieb Gürtner in dieser Unterredung nichts übrig, als Kerrls Erklärungen nochmals zusammenzufassen und ihn zu bitten, „heute von ihm eine Entscheidung nicht zu erwarten“.

Da Kerrl Gürtner als seinem Vorgesetzten in der staatlichen Hierarchie unter Berufung auf die Partei den Gehorsam verweigerte und drohte, die Arbeit des Reichsjustizministeriums auf dem Gebiet der Verreichlichung - mit der Gürtner schließlich von Hitler beauftragt worden war - sabotieren zu lassen, wurde eine abermalige Anrufung

4 Verm. Lammers' v. 31.5. 1934 (a.a.O.).

5 Vgl. „Vermerk über eine Unterredung zwischen den Herren Reichsjustizminister Dr. Gürtner und Preußischen Justizminister Kerrl, die am 31. Mai nachmittags in Gegenwart der Staatssekretäre stattgefunden hat" (a.a.O. und Akten der Reichskanzlei, a.a.O., Dok. Nr.354, S. 1300 ff.). 
der obersten, Staat und Partei verbindenden Entscheidungsgewalt Hitlers erforderlich. Schon am nächsten Tag bat Schlegelberger daher den Chef der Reichskanzlei um eine sofortige Unterredung ${ }^{6}$, in der er ihn von der "unerwarteten, scharfen Zuspitzung der Lage" informierte und ihm eine Aufzeichnung des Gesprächs zwischen Gürtner und Kerrl sowie eine Übersicht über den Stand der Verreichlichungsarbeiten übergab. Aber auch Kerrl ließ nicht locker und erreichte am 6. Juni einen Empfang bei Hitler. ${ }^{7}$ Gürtner, der zwei Tage später bei Hitler über gesetzliche Maßnahmen zur wirtschaftlichen Sicherung der Landesverteidigung Vortrag hielt, dürfte dabei ebenfalls Gelegenheit gehabt haben, Hitler seine Meinung nochmals vorzutragen. Da Hitler an seiner Entscheidung festhielt, blieb Kerrl schließlich nur übrig, seine Ankündigung wahr zu machen und sein Amt zur Verfügung zu stellen: Auf Vorschlag Görings in seiner Eigenschaft als Preußischer Ministerpräsident beauftragte Hitler durch Erlaß vom 16. Juni 1934 daraufhin Gürtner gleichzeitig mit der Wahrnehmung der Geschäfte des Preußischen Justizministers. ${ }^{8}$ Damit hatte sich die Initiative der Kerrl-Freisler-Gruppe gegen ihre Urheber selbst ausgewirkt. Freisler, dessen Stellung allerdings nach dem Abgang Kerrls nur an Bedeutung gewinnen konnte, widmete seinem Freund in der „Deutschen Justiz“ einen hymnischen Nachruf, in dem er Kerrls Verdienste während ihres fünfzehnmonatigen ,ununterbrochenen gemeinsamen Kampfes" hervorhob und sich und seine Mitarbeiter mit dem Hinweis tröstete, daß der Führer Kerrl für neue Aufgaben brauche, „die weit über den Rahmen Preußens“ hinausgingen, und daß es ferner für nationalsozialistische Kampfgenossen keine Trennung gebe, sondern nur ein erneutes Bekenntnis, ,im Kampfe um ein nationalsozialistisches Deutschland weiter fest, mutig und aufopferungsbereit zusammenzustehen ".9 Gleichzeitig richtete er jedoch an seinen neuen Herrn - Gürtner - im Namen aller Arbeiter, Angestellten und Beamten der preußischen Justiz eine Ergebenheitsadresse, die mit der Versicherung endete: „Treu werden wir unter Ihrer Führung arbeiten!“10

Statt der Unterstellung der bayerischen Justizverwaltung unter einen Preußen als Reichsjustizminister ${ }^{11}$ - wie es bei einer Verwirklichung der Absicht Kerrls der Fall gewesen wäre - hatte vielmehr Preußen jetzt einen Bayern als Justizminister bekommen. In seinem Antrittserlaß an die preußischen Justizbehörden bezeugte Gürtner nicht ohne diplomatisches Geschick seine „Ehrfurcht vor der ruhmreichen preußischen Überlieferung“ sowie seine „Achtung vor der hingebenden Arbeit, mit der die preußische Justiz zur Gestaltung eines volkstümlichen deutschen Rechts im neuen

${ }^{6}$ Bezeichnenderweise in einem von seinem persönlichen Ref. überbrachten eigenhändigen Schr. und mit der Bemerkung, daß eine telefonische Unterrichtung nicht möglich sei - ein deutlicher Hinweis auf die Telefonüberwachung durch Görings „Forschungsamt“. Handschr. Schlegelbergers vom 1.6.1934 (Akten der RK, BA, Sign. R 43 II/1505).

7 Verm. Lammers' vom 6.6.1934 (Akten der RK, a.a.O.).

${ }^{8} \mathrm{Vgl}$. Kerrls Rücktrittsgesuch an Göring vom 12. Juni 1934 sowie die anschließende Korrespondenz Görings mit Hitler bzw. der Reichskanzlei nebst den Entwürfen und Gegenentwürfen für die entsprechende Pressenotiz (Akten des Preußischen Staatsministeriums, GehStArch. Berlin, Rep.90).

9 R. Freisler, Trennung, Abschied von Hanns Kerrl? (DJ 1934, S. 787 f.). Kerrl nahm den Posten eines Reichsministers ohne Geschäftsbereich trotz seiner erwähnten, entgegenstehenden Erklärung an und wurde 1935 Leiter der „Reichsstelle für Raumordnung“, bis ihm durch Erlaß v. 16.7.1935 (RGBI. I, S. 1029) die kirchlichen Angelegenheiten übertragen wurden.

10 DJ 1934, S.785.

11 Hanns Kerrl stammte aus Niedersachsen. 
Staat entscheidend beigetragen“ habe, und begrüßte seine neuen Mitarbeiter "mit der Gewißheit vertrauensvoller Zusammenarbeit zum Segen des Reichs". ${ }^{12}$

Gerade anläßlich der Übergabe der Amtsgeschäfte des preußischen Justizministers an Gürtner sollte die Feindschaft zwischen den Rivalen Kerrl und Frank nochmals deutlich werden. In welche Situation der Reichsjustizminister dadurch geriet, sei im folgenden dargestellt: Nachdem das Ausscheiden Kerrls aus der Justiz feststand, entwickelte Frank eine auffallende Aktivität, sich in die Aufgaben des Reichsjustizministeriums wieder einzuschalten. Am 20. Juni besuchte er Gürtner im Ministerium und erklärte, daß er „durch wichtigere Organisationfragen an [der] Ausübung des Kommissariats bisher behindert gewesen" sei, drückte seinen Wunsch nach kameradschaftlicher „Arbeitsteilung“ aus und stellte sogar seine Teilnahme an den Beratungen der amtlichen Strafrechtskommission über ein neues Strafgesetzbuch in Aussicht, die er bisher aus Gründen der Konkurrenz boykottiert hatte. ${ }^{13}$ In der dreieinhalbstündigen Aussprache empfahl ihm Gürtner jedoch, „sich im Rahmen der [bisherigen] Kommissars-Zuständigkeit zu betätigen“. Am Morgen des 22. Juni 1934 - am Tage, an dem in Anwesenheit aller Angehörigen des preußischen Justizministeriums in der Wilhelmstraße die feierliche Übergabe der Amtsgeschäfte durch Kerrl an Gürtner erfolgen sollte - wiederholte Frank seinen Besuch und erneuerte sein Anliegen. Gürtners Frage, ob er eine "nach außen sichtbare Arbeitsteilung oder Delegation von Arbeitsgebieten" beanspruche, verneinte Frank $z$ war, forderte aber seine Mitwirkung bei der bevorstehenden Übergabe der preußischen Amtsgeschäfte auf den Reichsjustizminister. Gürtner bezweifelte seine eigene Kompetenz, dazu die Zustimmung zu erteilen, konnte aber Franks Gegenfrage, ob der Minister „etwas dagegen“ habe, schlechterdings nicht bejahen. Da Kerrl mit dem Auto aus Hannover noch nicht eingetroffen war, fuhr Staatssekretär Schlegelberger in die Wilhelmstraße, um Freisler auf die mögliche überraschende Teilnahme Franks vorzubereiten. Als der Versuch, Kerrl in Hannover noch telefonisch zu erreichen, scheiterte, fuhr Freisler ihm entgegen, erreichte ihn auf der Avus kurz vor Berlin und berichtete sofort ins Reichsjustizministerium, daß Kerrl eine Beteiligung Franks „für unmöglich halte“. Nachdem Kerrl seine Entscheidung dem Reichsjustizminister nochmals selbst telefonisch bestätigt hatte, gelang es Gürtner, dem Reichsjustizkommissar in letzter Minute die briefliche Mitteilung zukommen zu lassen, „bei der heutigen Erörterung der Einzelheiten des Aktes“ habe sich ergeben, daß die Übergabe „als eine rein preußische Angelegenheit behandelt werden“ und diese Tatsache ,auch äußerlich zum Ausdruck kommen" sollte: er bitte Frank, von seiner „Beteiligung an dem heutigen Akte abzusehen“ ${ }^{14}$ Ein öffentlicher Eklat hatte so gerade noch rechtzeitig verhindert werden können. Die Zusammenarbeit des Reichsjustizministers mit dem Reichsjustizkommissar wurde dadurch natürlich nicht gefördert: einen aggressiven Artikel von Franks Pressechef im nationalsozialistischen Blatt „Der Angriff“, der die Arbeit der Reichs- und Preußischen Justizverwaltung bei der Rechtserneuerung gegenüber der Arbeit der Deutschen Rechtsfront

12 DJ 1934, S.785.

13 Vgl. dazu Kapitel VII.2.a., S. $754 \mathrm{ff}$.

14 Schr. Gürtners an Frank v. 22.6.34, $13.30 \mathrm{Uhr}$; zu den Vorgängen vgl. Aufz. Schlegelbergers v. Juni 1934 (Akten des RJM, BA, Sign. R 22/4723). 
als untergeordnet abtat, nahm Gürtner zum Anlaß, seine Teilnahme an der Feier zum einjährigen Bestehen der Akademie für Deutsches Recht am 26. Juni abzusagen. ${ }^{15}$

Nachdem die drei „Ländergruppen“ seit der Dresdener Tagung bei der Vorbereitung eines einheitlichen Justizverwaltungsrechts bereits gute Arbeit geleistet hatten, entschloß sich Gürtner, der Personalunion zwischen dem Reichsjustizministerium und dem Preußischen Justizministerium möglichst bald auch die Realunion folgen zu lassen. Dadurch sollte die weitere Verreichlichung gefördert und zugleich der Grundstock für das erweiterte Reichsjustizministerium geschaffen werden, das einmal die oberstinstanzlichen Aufgaben der Justiz aller Länder übernehmen sollte. Nachdem für beide Ministerien, von denen das eine für die Gesamtheit und das andere immerhin für drei Fünftel des Reichsgebiets - wenn auch mit unterschiedlichen Aufgabengebieten - zuständig war, eine gemeinsame Spitze bestand, war es nur eine natürliche Folge, daß $z$ wischen ihnen auch eine engere organisatorische Verbindung hergestellt wurde. Mußte doch z. B. derselbe Referent, der ein Reichsgesetz bearbeitet hatte, am besten in der Lage sein, dafür auch eine preußische Durchführungsbestimmung zu entwerfen. Die rechtliche Grundlage für eine arbeitstechnische Verschmelzung beider Ministerien war die vom Reichsinnenminister am 19. Juli 1934 erlassene Erste Verordnung zur Vereinheitlichung und Verbilligung der Verwaltung ${ }^{16}$, in deren unscheinbarem Gewand sich „ein ganz gewaltiges Stück Reichsreform" ${ }^{17}$ verbarg. Nach dieser Verordnung konnte ein Minister, dem ein Reichs- und ein Landesministerium gemeinsam unterstellt waren, dem Personal beider Ministerien „die Erledigung von Dienstgeschäften ohne Rücksicht darauf übertragen, welchem der Ministerien ein Beamter, Angestellter oder Arbeiter angehört“. Das Verhältnis der Beamten zu ihrem jeweiligen Dienstherrn sowie das Dienst- und Arbeitsverhältnis der Angestellten und Arbeiter wurde durch diese Regelung allerdings noch nicht berührt.

Auf der Grundlage dieser Ermächtigung ordnete Gürtner durch einen Erlaß vom 16. Oktober $1934^{18}$, der ab 22. Oktober wirksam wurde, die Vereinigung der ,Justizministerien des Reichs und Preußens zu gemeinschaftlicher Arbeit" an. Nunmehr wurden „die Beamten des Reichsjustizministeriums verpflichtet, auch in Angelegenheiten des Preußischen Dienstes, die Beamten des Preußischen Justizministeriums auch in Angelegenheiten des Reichsdienstes tätig zu werden“, das gleiche galt für die Angestellten und Arbeiter. Um zeitraubende Probleme auszuklammern, die nur im Zusammenwirken mit anderen Ministerien und daher erst bei einer endgültigen Verreichlichung gelöst werden konnten, blieben beide Ministerien zunächst personell und haushaltsmäßig weiter getrennt: die einzelnen Beamten blieben Reichs- oder preußische Beamte und die gesonderten Haushaltspläne wurden beibehalten. Die Sachausgaben wurden anteilig verrechnet, sowie es sich nicht eindeutig um Reichs- oder preußische Aufgaben handelte. Ganz gleich, in welcher seiner beiden Eigenschaften das Ministerium auftrat, führte es nur noch die einheitliche Bezeichnung: „Der Reichs- und Preußische Justizminister".

15 Schr. Gürtners an Frank v. 23.6.34 (a.a.O.).

16 RGBl. I, S.719.

17 So MinRat im RMdI Medicus, Reichsverwaltung und Landesverwaltung (Die Verwaltungsakademie, Bd. II, Beitrag 23, Berlin o.J., S.7).

18 DJ 1934, S. 1295. 
Da die Aufgaben des Reichs und Preußens nunmehr vom gesamten Beamtenstab wahrgenommen wurden, wurde eine neue Verteilung der Geschäfte auf die Referenten und eine Neugliederung des Ministeriums notwendig. Die drei bisherigen Abteilungen des Reichsjustizministeriums ${ }^{19}$ blieben bestehen, da ihre Aufgaben bei der Reichsgesetzgebung von der Verreichlichung nicht berührt wurden. Ihnen wurden jedoch die mit entsprechenden Aufgaben in Preußen betrauten Sachbearbeiter zugeordnet. Die Justizverwaltungsaufgaben für Preußen wurden drei weiteren Abteilungen übertragen. Nach Gürtners Erlaß über die Geschäftsführung vom 16. Oktober $1934^{20}$ gliederte sich das Ministerium nunmehr wie folgt:

Abt. I: Personalsachen und Gerichtsorganisation (MinDir. Nadler)

Abt. II: Strafgesetzgebung und bäuerliches Recht (MinDir. Schäfer)

Abt. III: Strafrechtspflege (Einzelsachen) und Strafvollzugsverwaltung (MinDir. Crohne)

Abt. IV: Bürgerliches Recht und bürgerliche Rechtspflege (MinDir. Volkmar)

Abt. V: Handelsrecht, Verkehrsrecht, öffentliches Recht und Völkerrecht (MinDir. Richter)

Abt. VI: Preußische Haushalts- und Verwaltungssachen (MinDirig. Schneller)

Dazu kamen die Abteilungen RJP (Präsident Palandt) und LA (MinDirig. Klässel). Erstere wurde durch das Reichsjustizprüfungsamt gebildet, das durch Erlaß vom 21. September 1934 zur Oberaufsicht über die erste juristische Prüfung und zur Abnahme der großen juristischen Staatsprüfung im ganzen Reich errichtet worden war und gleichzeitig die ministeriellen Angelegenheiten des Ausbildungswesens bearbeitete; es erhielt später die Bezeichnung Abt. VII (Ausbildung). Die Abt. LA war das preußische Landesamt für Familiengüter und Hausvermögen. Als Vertreter Gürtners stand Freisler als Staatssekretär nun gleichberechtigt neben Schlegelberger. Ihm wurden die Abteilungen II, III, VI und RJP unterstellt, Schlegelberger die Abteilungen IV, $\mathrm{V}$ und LA. In die Abteilung I teilten sich beide mit genau abgegrenzten Zuständigkeiten, bei Personalangelegenheiten leitender Beamter bestand die Regelung gegenseitiger Mitzeichnung. Über den beiden Zentralabteilungen der Staatssekretäre (ZS und $\mathrm{ZF}$ ), denen je ein Referat für Angelegenheiten der Verreichlichung unter Ministerialrat Sauer bzw. Oberlandesgerichtsrat Haastert zugeteilt war, stand das von Oberregierungsrat von Dohnanyi geleitete Ministerbüro Gürtners. Dem Ministerium gehörten nunmehr rund 100 Sachbearbeiter, davon 31 Ministerialräte, an. Die Dienststellen des Ministeriums wurden auf die Gebäude des Reichsjustizministeriums in der Voßstraße 5 und des Preußischen Justizministeriums in der Wilhelmstraße 65 verteilt nicht ohne Schwierigkeiten, da diese Gebäude schon bisher keinen ausreichenden Raum geboten hatten. Sitz des Ministeriums wurde die Wilhelmstraße 65, in der die meisten Abteilungen und auch das Ministerbüro untergebracht wurden. Die Voßstraße beherbergte die Abteilungen IV, RJP und LA.

19 Vgl. voranstehend S.86.

${ }^{20}$ Akten des RFiM (BA, Sign. R 2/23901). Der ab 20.10.34 gültige Geschäftsverteilungsplan ist im Anhang als Anl. 1 wiedergegeben. 


\section{Die Ausarbeitung eines einheitlichen Justizverwaltungsrechts und die Überleitungsgesetze vom Dezember 1934 und Januar 1935}

Die Übergangslösung, bei der die personellen, disziplinarischen und etatmäßigen Angelegenheiten der preußischen Justizverwaltung weiter landesrechtlich geregelt blieben, war zur Vermeidung von Doppel- und Gegeneinanderarbeit der beiden großen Ministerien sicher berechtigt. Wenn jedoch die Verreichlichung durch die Ernennung Gürtners zum Justizminister bzw. -senator auch in den anderen Ländern vorangetrieben werden sollte, so mußte möglichst bald ein einheitliches Justizverwaltungsrecht zur Verfügung stehen, da ein längeres Nebeneinander von Reichsrecht und dem recht buntscheckigen Landesrecht auf dem Gebiet der Justizverwaltung zwangsläufig zu höchst unklaren und komplizierten Verhältnissen geführt hätte. Die Schaffung eines solchen Reichsjustizverwaltungsrechts war daher eine unentbehrliche Voraussetzung für die endgültige Verreichlichung der Justiz. Auf diesem Gebiet waren die Arbeiten nach dem Dresdener Plan unterdessen vorangeschritten. Gemäß diesem Plan sollten mit der Sammlung und Sichtung der geltenden Länderbestimmungen nicht das Reichsjustizministerium belastet, sondern die sachkundigen Kräfte der Länder selbst betraut werden. Damit die drei gebildeten „Ländergruppen“ dabei nach einheitlichen und vergleichbaren Gesichtspunkten arbeiteten, ließ das Reichsjustizministerium den drei führenden Landesjustizverwaltungen Preußen, Sachsen und Bayern zwischen Februar und August 1934 elf „Zusammenstellungen“ zugehen, in denen Fragestellungen zu bestimmten Sachgebieten formuliert waren. Diese Zusammenstellungen betrafen: (1) das Beamten- und Besoldungswesen, (2) Vorbildung und Laufbahn der juristischen Beamten, (3) Umfang der Justizzuständigkeit und Wahrnehmung justizfremder Aufgaben, (4) Haushaltswesen, (5) Kassenwesen, (6) Altersschichtung im höheren Dienst, (7) Arbeits- und Dienstbetrieb in den Gefangenenanstalten, (8) Behandlung weiblicher Justizbeamter, (9) Laufbahn und Arbeitsbereich der Amtsanwälte, (10) Dienstverhältnisse der Strafvollzugsbeamten und (11) Dienst- und Geschäftsordnung der Gerichtsvollzieher. Dazu kamen noch Rundschreiben mit Fragen über Sondergebiete, wie z.B. Dienstvorschriften und Verwaltungsanweisungen für Strafsachen, Haushaltspläne, Rechtshilfe bei der Vollstreckung von Freiheitsstrafen, Übertragung von Geschäften des Strafvollzugs auf Beamte des mittleren Dienstes, Strafregisterwesen und bestimmte Gegenstände des Handelsrechts. ${ }^{1}$ Jedes der drei führenden Länderministerien beantwortete einmal diese Fragen für sein eigenes Land, gab sie zum anderen aber an die Chefs der anderen Justizverwaltungen seiner Gruppe weiter und erbat von diesen Auskunft über die geltenden einschlägigen Bestimmungen sowie etwaige Vorschläge für eine Neuregelung im künftigen Reichsjustizverwaltungsrecht. Auf Anregung des hamburgischen Justizsenators Rothenberger einigten sich die Hansestädte Hamburg, Bremen und Lübeck, gegenüber dem Preußischen Justizministerium möglichst geschlossen aufzutreten und „zu den jeweils zur Erörterung stehenden Fragen tunlichst einheitlich Stellung zu nehmen“, um „die hansestädtischen Belange bei der

\footnotetext{
1 Die „Zusammenstellungen“ und Rundschreiben sowie ihre Bearbeitung durch die Gruppe Nord siehe Akten des Preußischen Justizministeriums (GehStArch. Berlin, Rep. 84 a, Nr. 4365-4383).
} 
Schaffung des neuen Justizverwaltungsrechts" zu wahren. ${ }^{2}$ Aufgrund der einlaufenden Äußerungen der einzelnen Justizverwaltungen gaben die drei führenden Justizministerien eine Darstellung der in Nord-, Mittel- und Süddeutschland auf den einzelnen Sachgebieten bestehenden Regelungen an das Reichsjustizministerium. Die von den Landesjustizverwaltungen eingereichten Vorscbläge für eine Neugestaltung oder Beibehaltung von Regelungen wurden innerhalb jeder der drei Gruppen - meist auf einberufenen Besprechungen - nach Möglichkeit zu "gemeinsamen Vorschlägen“ der jeweiligen Gruppe abgestimmt. Wo eine solche Einigung nicht gelang, wurde die gesonderte Stellungnahme der betreffenden Justizverwaltung vermerkt. ${ }^{3}$ Am engsten scheint dabei die Gruppe der süddeutschen Länder zusammengearbeitet zu haben, die zahlreiche gemeinsame Beratungen abhielt und in ihren Berichten stets betonte, daß ihre Vorschläge "auf einstimmiger Beschlußfassung“ beruhten. ${ }^{4}$ Auf der Grundlage dieser von den Gruppen eingereichten Unterlagen arbeitete das Reichsjustizministerium die neuen Bestimmungen aus, die künftig für das ganze Reich gelten sollten, und ergänzte die bereits bestehenden reichsrechtlichen Bestimmungen z. B. des Beamten-, Besoldungs-, Haushalts- und Kassenrechts so, daß sie auch den Bedürfnissen der Justiz gerecht wurden. Die ausgearbeiteten Entwürfe gingen den obersten Landesbehörden meist nochmals zur Stellungnahme zu. Dabei war das Ministerium bestrebt, die neu geschaffenen Regelungen - auch soweit sie zunächst Teilregelungen darstellten - so bald wie möglich in Kraft treten zu lassen. Ohne auf den materiellen Inhalt der reichsrechtlichen Neuregelungen einzugehen, sei nur auf einige Verordnungen zur Vereinheitlichung hingewiesen, die Gürtner aufgrund seiner Ermächtigung durch das erste Überleitungsgesetz noch im Jahre 1934 erließ: die Verordnung über den Vollzug von Freiheitsstrafen vom 15. Mai ${ }^{5}$, die das Strafvollzugsrecht bis zu einem endgültigen Reichsgesetz verreichlichte; die Verordnung zur Vereinheitlichung der Zuständigkeit in Familien- und Nachlaßsachen vom 31. $\mathrm{Mai}^{6}$, die die Zersplitterung auf dem Gebiet des Familienrechts beseitigte; die Verordnung über die Reichsnotarkammer vom 17. Juli ${ }^{7}$, die der Vereinheitlichung des Notarwesens diente; die Justizausbildungsordnung vom 22.Juli ${ }^{8}$, die die Ausbildung der Justizbeamten und Richter für das Reich regelte; und die Aktenordnung vom 28 . November', die durch eine gleichmäßige Verwaltung des Schriftguts einen einheitlichen Geschäftsbetrieb bei den Gerichten und Staatsanwaltschaften ermöglichte.

Daß nicht alle Verreichlichungsmaßnahmen in den Ländern auf ungeteilte Aufnahme stießen und dem Reichsjustizministerium dabei gelegentlich auch Konzessionen abgerungen wurden, zeigte sich z.B. bei der Zentralisierung der Juristenausbil-

2 Akten des OLG Hamburg (StArch. Hamburg, Best. 213-1).

${ }_{3}$ Das Verfahren wird aus den Akten des preuß. JM (GehStArch. Berlin, Rep. 84a/4365-4383) ersichtlich, das zum Zwecke der Information auch Abschriften der Besprechungsprotokolle und Stellungnahmen der mittelund süddeutschen Gruppen zugesandt erhielt.

4 Vgl. die Ber. des Bayer. Staatsministeriums der Justiz an das RJM vom 18.6., 25.6. und 3.7.1934 (Akten des preuß. JM, a.a.O., 4373 und 4374). Das Verfahren wurde auf der Besprechung der süddeutschen Justizverwaltungen am 20.2.1934 in München vereinbart (a.a.O., 4365).

${ }^{5}$ RGBI. I, S. 383.

${ }^{6}$ RGBl. I, S.472, nebst Durchf.VO v. 27.7.1934 (RGBl.I, S. 738).

7 RGBI.I, S.712. Ihre Satzung s. Bekanntmachung des RuPrJM v. 14.11.1934 (DJ 1934, S. 1492).

${ }^{8}$ RGBI.I, S. 727.

9 AV d. RuPrJM (DJ 1934, S. 1492). 
dung. Als im September 1934 die in der erwähnten Justizausbildungsordnung als Möglichkeit vorgesehenen Zweigstellen des Reichsjustizprüfungsamts zur Abnahme der großen Staatsprüfung - „vorübergehend“ - in München, Stuttgart, Dresden und Hamburg errichtet wurden ${ }^{10}$, protestierte der thüringische Justizminister Weber - seit Mai 1933 im Amt und eingeschworener Nationalsozialist ${ }^{11}$ - gegen die Zuständigkeit der Dresdener $Z$ weigstelle auch für Thüringen und forderte die Einrichtung einer eigenen Zweigstelle beim Oberlandesgericht Jena. Da er von dem im Reichsjustizministerium für Ausbildungsfragen zuständigen Freisler abschlägig beschieden wurde, wandte er sich in einem Schreiben vom 13. Oktober 1934 direkt an Hitler. Der thüringische Reichsstatthalter und Gauleiter Sauckel bat Lammers in einem Begleitschreiben ausdrücklich, Hitler den Bericht Webers vorzutragen. ${ }^{12}$ In seinem Schreiben betonte Weber, die Zusammenfassung der obersten Behörden dürfe „nicht überspannt werden“. Sie sei vor allem dann falsch, wenn die Aufgabe von kleineren Behörden besser gelöst werden könne, und er sei überzeugt, „daß Prüfungsämter, die den Prüfling persönlich kennen, bessere Arbeit leisten als ein größeres Prüfungsamt, das nur auf Grund der Akten und nach dem kurzen persönlichen Eindruck in der mündlichen Prüfung urteilt“. Diejenigen Richter des Oberlandesgerichts Jena, die Mitglieder des Prüfungsamts seien, könnten über Charakter, Lebensauffassung und "das richtige Gefühl für die Volksgemeinschaft" des Prüflings - auf deren Beurteilung es im nationalsozialistischen Staat ebenso ankomme wie auf das Fachwissen - durch die Beobachtung des Referendars während seines Vorbereitungsdienstes am besten urteilen. Da sie aus ihrer Tätigkeit ferner die Richter der Untergerichte ihres Bezirks kennen, wüßten sie auch, wie deren Zeugnisse zu bewerten seien. Das Endziel, ein einziges Amt in Berlin für das ganze Reich mit der Abnahme der großen juristischen Staatsprüfung zu betrauen, würde gegenüber dem früheren Zustand eine wesentliche Verschlechterung bedeuten, die Vorteile des kleineren Bezirks eines Prüfungsamts gingen aber schon dann verloren, „wenn die Länder Sachsen und Thüringen zu einem Prüfungsbezirk vereinigt werden “. ${ }^{13}$ Nach Vortrag durch Lammers ließ Hitler diesen Bericht an das Reichs- und Preußische Justizministerium weiterleiten. Am 20. November 1934 nahm Freisler gegen die Errichtung einer Zweigstelle in Jena ziemlich dezidiert Stellung. Sein Antwortschreiben an Lammers sei hier auführlicher wiedergegeben, da es das radikale Denken dieses Mannes und die rigorosen Zentralisierungsbestrebungen der Kerrl-Freisler-Gruppe - die sich von der ausgewogeneren Verreichlichungskonzeption Gürtners unterschieden - deutlich charakterisiert:

„Bei Neuordnung des juristischen Prüfungswesens bin ich davon ausgegangen, daß die Reform des deutschen Rechts mit in erster Linie eine Frage der Ausbildung der jungen Juristen, eine Frage der Männer ist, die deutsches Recht gestalten und anwenden sollen, und daß ein einheitliches deutsches Recht einen einheitlich ausgebildeten Rechtswahrerstand zur Voraussetzung hat ... Der Geist, der das Prüfungsamt beherrscht, überträgt sich auf die ausbildenden Stellen und die Anforderungen, die das Prüfungsamt stellt, sind die Richtschnur für Lehrende und Lernende.

$10 \S 57$ der 1. Durchf.VO v. 13.9.1934 (RGBl.I, S.831).

11 Vgl. die Ausführungen bei H. Weinkauff, a.a.O., S.98f.

12 Schr. Webers v. 13.10.1934 und Sauckels v. 20.10.1934 (Akten der RK, BA, Sign. R 43 II/1506).

13 Schr. Webers, a.a.O. 
Es war deshalb notwendig, für ganz Deutschland ein einheitliches Prüfungsamt unter einheitlicher Leitung zu schaffen. Die Zweigstellen sind nur ein Notbehelf und eine Übergangsmaßnahme; sie erschweren das Einhalten einer einheitlichen Linie, mußten aber in Kauf genommen werden, um den Übergang des Prüfungswesens von den Ländern auf das Reich zu überbrücken. Eine ausschlaggebende und bleibende Bedeutung kommt den Zweigstellen aber nicht zu.“

Die Wünsche der Länder müsse er „zurückstellen hinter dem Reichsgedanken“. Auch die Gründe, die Weber für seine Forderung geltend mache, könnten ihn nicht überzeugen: im Gegenteil bestehe die Gefahr, daß Prüfer, die ihre Prüflinge von der Vorbereitungszeit her kennen, diesen „nicht mit der wünschenswerten Unbefangenheit“ gegenüberstünden. Freisler schloß mit der übertriebenen Feststellung, daß die Errichtung der geforderten Zweigstelle in Jena „den Weg zur Reichseinheit gefährden" würde, und bat Lammers, seinen Kampf für eine einheitliche deutsche Justiz auch in diesem Punkt zu unterstützen. ${ }^{14}$ Obwohl sich auch Reichsjustizkommissar Frank für die Forderung Webers einsetzte ${ }^{15}$, unterblieb die Einrichtung der Zweigstelle in Jena. Aber als Freisler im Januar 1935 seine Ankündigung wahr machte und auch die anderen Zweigstellen des Reichsjustizprüfungsamtes mit Wirkung vom 1. März aufhob ${ }^{16}$, mußte er eine Niederlage einstecken. Diese Maßnahme löste unter dem juristischen Nachwuchs erhebliche Beunruhigung aus, und vor allem die süddeutschen Referendare fühlten sich gegenüber ihren preußischen Kollegen benachteiligt. Für sie hatte bereits die Justizausbildungsordnung vom Juli 1934 hinsichtlich der großen Staatsprüfung eine grundlegende Änderung ihrer bisherigen Prüfungsart gebracht, während wesentliche Züge der preußischen Prüfungseinrichtungen in die reichseinheitliche Regelung übernommen worden waren. Nunmehr befürchteten sie, unter Anlegung desselben Prüfungsmaßstabs mit den preußischen Kandidaten konkurrieren zu müssen, und zwar in einer fremden Umgebung und vor überwiegend norddeutschen Prüfern, deren Dialekt und Ausdrucksweise sich von den ihrigen erheblich unterschieden. Dazu kam, daß die Prüfungskosten durch die erforderlich gewordene Reise und den Aufenthalt in Berlin für die meisten nur sehr schwer aufzubringen waren. Diese Auswirkungen beunruhigten auch die Eltern und Angehörigen der Betroffenen, so daß sich in weiten Bevölkerungskreisen eine der Verreichlichung abträgliche Stimmung bemerkbar machte. Diese nachteiligen politischen Folgen wurden z.B. vom Beauftragten ${ }^{17}$ für die Abteilung Württemberg-Baden an das Reichsjustizministerium berichtet. ${ }^{18}$ Auch Hans Frank äußerte auf der ersten Sitzung des Reichskabinetts, an der er als neu ernannter Reichsminister ${ }^{19}$ teilnahm, „die dringende Bitte, mit Rücksicht auf die sehr beschränkten Vermögensverhältnisse des größten Teils der Referendare, die Justizprüfungsämter in München und Hamburg zu erhalten“. Er stieß sofort auf den Widerstand seines Gegners Kerrl, der sich gegen die-

14 Schr. Freislers an Lammers v. 20.11.1934 (Akten der RK, a.a.O.).

15 Diensttageb. des RJM, Bd. 1, Eintr. v. 30.10.1934 (BA, Sign. R 22/131).

16 AV d. RJM (RJP) v. 11.1.1935 (DJ 1935, S. 93). Vom 1.3.1935 ab sollten dort nur noch diejenigen Referendare geprüft werden, die vor dem 1.11.1934 zur zweiten juristischen Staatsprüfung zugelassen worden waren. Spätestens mit dem 30.6.1935 sollte jedoch jegliche Tätigkeit der Zweigstellen beendet sein.

17 Uber die „Beauftragten des Reichsministers der Justiz“ vgl. im folgenden S. $112 \mathrm{f}$.

18 MinDir. Thiesing, Drei Monate als Beauftragter des Reichsministers der Justiz für die Abteilung Württemberg-Baden (DJ 1935, S.704 ff., 706). Auch der Beauftragte für Sachsen-Thüringen machte das RJM am 15.1.1935 auf die wirtschaftliche Notlage der Referendare aufmerksam (Diensttageb. des RJM, Bd. 1, Eintr. v. 24.1.1935, BA, Sign. R 22/131).

$19 \mathrm{Vgl}$. im folgenden S. 115. 
sen Antrag aussprach und daran erinnerte, daß er auch das Gemeinschaftslager der Referendare in Jüterbog ,gerade mit Rücksicht auf die Vereinheitlichung auch bei den Referendaren" geschaffen habe. ${ }^{20}$ Wenn in dieser Kabinettssitzung darüber auch noch keine Entscheidung fiel, so setzte Gürtner am 27.Februar 1935 eine Verordnung durch, die als Ersatz für die aufgehobenen Zweigstellen örtliche Prüfungsstellen in Berlin, Dresden, Düsseldorf, Hamburg, München und Stuttgart errichtete. ${ }^{21}$ Dabei blieb die Einheitlichkeit des Prüfungswesens völlig gewahrt, indem das Reichsjustizprüfungsamt die Aufgaben stellte, die Prüfungsstellen beaufsichtigte und der Präsident des Reichsjustizprüfungsamtes oder ein von ihm bestimmter Vertreter bei jeder Prüfungsstelle den Vorsitz in der mündlichen Prüfung übernehmen konnte. Auch ohne Zentralisierung der Prüfung bei einer Stelle wurde durch diese Handhaben garantiert, daß im ganzen Reich nach gleichen Grundsätzen verfahren und nach gleichem Maßstab geurteilt wurde.

Während die Arbeiten am Justizverwaltungsrecht vorangingen, entschloß sich Gürtner, den nächsten Schritt zur organisatorischen Vereinheitlichung zu tun und die unmittelbare Leitung der Justizverwaltung auch in den außerpreußischen Ländern zu übernehmen. Am 23. November 1934 leitete er der Reichskanzlei den Entwurf eines „Zweiten Gesetzes zur Überleitung der Rechtspflege auf das Reich“ zu und bat, die Beschlußfassung darüber schon auf die Tagesordnung der nächsten Kabinettssitzung zu setzen.

Nachdem der Entwurf von der Reichskanzlei befürwortet worden war, ließ ihn Lammers an die Kabinettsmitglieder verteilen. ${ }^{22}$ Auf der nächsten Sitzung der Reichsregierung, die am Nachmittag des 4. Dezember 1934 in der Reichskanzlei stattfand, trug Gürtner in Anwesenheit Hitlers den Inhalt des Entwurfs vor. Einwände wurden von keiner Seite vorgebracht; Reichsfinanzminister Graf Schwerin von Krosigk äuBerte lediglich die Bitte, die im Entwurf vorgesehene etatrechtliche Regelung für die nachgeordneten Justizbehörden als eine Übergangslösung anzusehen. Daraufhin stimmte Hitler dem Entwurf zu. ${ }^{23}$ Das Gesetz wurde am nächsten Tag von Hitler, Gürtner und Frick unterschrieben und trat am 1.Januar 1935 in Kraft. ${ }^{24}$

Gemäß diesem Gesetz gingen die Zuständigkeiten der obersten Landesjustizbehör$\operatorname{den}^{25}$ auf den Reichsjustizminister über, der sie auf nachgeordnete Behörden übertragen konnte $(\S 1)$. „Zur überleitenden Fortführung der Geschäfte“ - d.h. für die UUbergangszeit - konnte er für einzelne oder mehrere Länder oder Landesteile „Beauftragte des Reichsministers der Justiz“ einsetzen, deren Dienststellen als (Territorial-)Abteilungen neben die bestehenden (Sach-)Abteilungen des Reichsjustizministeriums traten $(\S 2)$. Die Beamten, Hilfskräfte und Einrichtungen der bisherigen obersten Landes-

20 Niederschr. über die Sitzung des Reichskabinetts am 24.1.1935 (Akten der RK, Regierung Hitler, Bd. II.1, Dok. Nr. 85, S. 324 f.). Zum Referendarlager vgl. Kapitel III.4.b., S. 303 ff.

21 VO über den Ausbau des Reichs-Justizprüfungsamtes (RGB1. I, S.342).

22 Vgl. dazu Akten der RK (BA, Sign. R 43 II/1505).

22 Niederschr. der Sitzung (Akten der RK. Regierung Hitler, Bd. II.1, Dok. Nr. 53, S. 205).

24 RGBI. I, S. 1214.

25 Dazu gehörten auch jene Zuständigkeiten in Justizangelegenheiten, die bisher von der Landesregierung (Gesamtministerium) wahrgenommen wurden, nicht jedoch die Befugnisse betr. Ernennung und Entlassung unmittelbarer Landesbeamter und betr. Ausübung des Begnadigungsrechts, die den Ländern rückübertragen worden waren (VO zur Úberleitung der Rechtspflege auf das Reich v. 20.12.1934, RGBl.I, S. 1267). Diese Ausnahmen fielen jedoch durch die entsprechenden zwei Erlasse Hitlers v. 1.2.1935 (RGB1. I, S. 73 f.) fort. 
behörden standen den Beauftragten als Dienststellen zur Verfügung. Wie bei der $\mathrm{Zu}$ sammenlegung des Reichs- und des Preußischen Justizministeriums blieben auch hier die beamten-, verwaltungs- und haushaltsrechtlichen Verhältnisse zunächst unberührt: so bestand z. B. auch die Zuständigkeit der Reichsstatthalter zur Ernennung und Entlassung der Beamten fort ${ }^{26}$, ferner mußten die Kosten der Justizverwaltung weiter von den Ländern getragen werden, d.h. die im Landeshaushalt für die bisherige oberste Landesjustizbehörde bereitgestellten Mittel mußten dem Reichsjustizminister zur Verfügung bleiben $(\S 3)$.

Die in $\S 1$ des Gesetzes vorgesehene Übertragung von Befugnissen auf nachgeordnete Behörden - Oberlandesgerichtspräsidenten und Generalstaatsanwälte - war vor allem in kleineren Ländern geboten, wo die Zuständigkeiten in starkem Maße bei den obersten Landesbehörden zentralisiert waren. Um die nachgeordneten Behörden gleich mit den dafür erforderlichen Mitarbeitern auszustatten, mußten entsprechende Kräfte von den obersten Landesbehörden abgezweigt werden. Die beamtrenrechtliche Voraussetzung für diese Umbesetzung wurde geschaffen, indem jene Bestimmungen des Reichsgesetzes vom 30.Juni $1933^{27}$ für anwendbar erklärt wurden $(\S 4)$, die eine Verwendung von Beamten unter Belassung von Amtsbezeichung und Gehalt in einem geringer besoldeten Amte gestatteten, wenn es beim Übergang von Aufgaben an eine andere Behörde notwendig wurde.

Noch am selben Tag, an dem das Gesetz unterzeichnet wurde, legte Gürtner die neu zu errichtenden Abteilungen - die besser als „Außenstellen“ des Reichsjustizministeriums bezeichnet werden können - fest $^{28}$; am 19. Dezember bestellte er die vorgesehenen Beauftragten ${ }^{29}$ :

1. Abteilung Bayern (Beauftragter: Bayerischer Staatsrat Spangenberger in München),

2. Abteilung Sachsen-Thüringen (Beauftragter: Sächsischer Justizminister Thierack in Dresden),

3. Abteilung Württemberg-Baden (Beauftragter: Preußischer Ministerialdirektor Thiesing),

4. Abteilung Nord für die Länder Hamburg, Mecklenburg, Oldenburg (ohne Birkenfeld), Bremen und Lübeck (Beauftragter: Hamburgischer Senator Rothenberger).

In den restlichen fünf Ländern Hessen, Braunschweig, Anhalt, Lippe und Schaumburg-Lippe wurden die Aufgaben der obersten Landesjustizbehörden unmittelbar vom Reichsjustizministerium wahrgenommen. ${ }^{30}$ Hier wurden den zuständigen Oberlandesgerichtspräsidenten und Generalstaatsanwälten die auf den Reichsjustizminister übergegangenen Zuständigkeiten der obersten Landesbehörden in demselben Ausmaß übertragen, wie es in Preußen schon seit jeher geregelt war; denn die preußische Justizverwaltung hatte wegen ihres Umfanges als einzige eine weitgehende Dezentralisation entwickelt, die der Reichsjustiz als Modell dienen konnte.

26 Bis zum Erlaß des Reichsstatthaltergesetzes v. 30.1.1935 (RGBI.I, S.65).

${ }^{27}$ Gesetz zur Änderung von Vorschriften auf dem Gebiete des allgemeinen Beamten-, des Besoldungs- und des Versorgungsrechts (RGB1. I, S.433).

28 VO d. RJM v. 5.12.1934 (DJ 1934, S. 1525).

29 Mitteilung des RJM an die Obersten Reichsbehörden vom 19.12.1934 (Akten der RK, BA, Sign. R 43 II/ 1505).

30 2. AV d. RJM zur Durchführung des Zweiten Ưberleitungsgesetzes vom 18.12.1934 (DJ 1934, S. 1608). 
Das zweite Überleitungsgesetz brachte somit die rechtliche Zusammenfassung der Justizverwaltungen aller Länder an der Spitze und die Beseitigung der Landesjustizministerien ab 1.Januar 1935.

Neben der Fortführung der laufenden Geschäfte nach der Weisung Gürtners hatten die vier ernannten Beauftragten daher die Aufgabe, die Justizministerien aufzulösen und die vollständige Übernahme der Justizverwaltungen ihrer Länder durch das Reich vorzubereiten. Diese Auflösung geschah durch die Abgabe von Zuständigkeiten sowohl nach unten wie nach oben: Einmal sollten die Beauftragten für die Abgabe aller hierfür geeigneten Geschäfte an die Provinzialbehörden, d.h. an die Oberlandesgerichtspräsidenten und Generalstaatsanwälte sorgen. Zum anderen übernahm das Reichsjustizministerium eine Reihe dieser Zuständigkeiten mit Wirkung vom 1. Januar 1935 selbst. So wurden sämtliche Aufgaben der obersten Landesjustizbehörden auf dem Gebiet der Strafgesetzgebung und der Strafrechtspflege einschließlich der Strafvollzugsverwaltung der Bearbeitung durch die Beauftragten entzogen und den entsprechenden Abteilungen des Reichsjustizministeriums in Berlin übertragen. ${ }^{31}$ Das hatte z.B. zur Folge, daß die Oberlandesgerichtspräsidenten und Generalstaatsanwälte in politischen oder sonstigen Strafsachen von Bedeutung nunmehr unmittelbar an den Reichsjustizminister berichteten und gegebenenfalls dessen Weisung einholten. Ferner übernahm die Zentrale in Berlin die oberste Aufsicht über alle Gefangenenanstalten und den gesamten Vollzug: für den Bezirk jedes Oberlandesgerichts übte diese Überwachung nunmehr der jeweilige Generalstaatsanwalt unmittelbar im Auftrage des Reichsjustizministers aus. ${ }^{32}$ Ebenso wurden die entsprechenden Abteilungen des Ministeriums in Berlin mit den bisherigen Aufgaben der obersten Landesjustizbehörden auf dem Gebiet des Erbhofrechts ${ }^{33}$ und des Ausbildungswesens ${ }^{34}$ sowie mit der Entscheidung über die Ersuchen ausländischer Regierungen um Rechtshilfe in Strafsachen betraut. ${ }^{35}$ Gleichzeitig erfolgte die Vereinheitlichung der Staatsanwaltschaft; ihr Aufbau, ihre Gliederung, die Aufsicht und Leitung sowie die Geschäftsverteilung ihrer Behörden wurden im ganzen Reich einheitlich geregelt. Die oberste Aufsicht und Leitung der Staatsanwaltschaft übernahm nunmehr ebenfalls der Reichsjustizminister. ${ }^{36}$ Später wurden den Beauftragten auch noch die Angelegenheiten der Rechtsanwälte entzogen. ${ }^{37}$ Die Tätigkeit der vier Beauftragten betraf also im wesentlichen nur noch das Personalwesen und die Beaufsichtigung der Zivilrechtspflege sowie der freiwilligen Gerichtsbarkeit. ${ }^{38}$

Vom Personal der aufzulösenden Landesjustizministerien wurde ein Teil für die Bearbeitung der auf die Oberlandesgerichte übergegangenen Verwaltungsgeschäfte benötigt, ein Teil wurde in freie Stellen nachgeordneter Justizbehörden versetzt, ein weiterer Teil trat in andere Verwaltungen über oder in den Ruhestand. Einige Beamte wur-

31 1.AV d. RJM v. 18.12.1934 (a.a.O., S. 1607) mit Ausnahme jener Gnadensachen, für die sich die Reichsstatthalter die Ausübung des Gnadenrechts vorbehalten hatten. Sie wurden von den Beauftragten weiterbearbeitet.

32 4.AV d. RJM v. 18.12.1934 (a.a.O., S. 1612).

33 7.AV d. RJM v. 18.12.1934 (a.a.O., S.1614).

${ }^{34}$ AV d. RJM v. 18.12.1934 (a.a.O., S. 1614).

35 5.AV d. RJM v. 18.12.1934 (a.a.O., S. 1613).

36 3. AV d. RJM v. 18.12.1934 (a.a.O., S. 1608).

37 AV d. RJM v. 16.1.1935 (DJ 1935, S.94).

38 Vgl. dazu auch G. Thierack, Die Aufgaben der Beauftragten des Reichsministers der Justiz (DJ 1935, S.3), und Thiesing, a.a.O., S. $704 \mathrm{ff}$. 
den in das Reichsjustizministerium berufen, das durch die nach Berlin übernommenen Geschäfte verstärkt werden mußte. So trat zum Jahresanfang 1935 eine Anzahl Ministerialbeamter aus den nichtpreußischen Ländern ins Reichsjustizministerium ein und wurde in die bestehenden Abteilungen eingegliedert. ${ }^{39}$ Wie Gürtner in seiner Rede zur offiziellen Übernahme der bayerischen Justizverwaltung am 4.Januar 1935 im Münchner Justizpalast betonte, sollte sich in diesen Berufungen bereits der Gedanke auswirken, daß die landsmannschaftliche Zusammensetzung des Reichsjustizministeriums künftig einen "Querschnitt durch die Juristenschaft des Reiches“ darzustellen habe. ${ }^{40}$

Der „Abschied von den Landesjustizverwaltungen “ ${ }^{“ 11}$ vollzog sich in der Form feierlicher Festakte, an denen jeweils die Reichsstatthalter, die Mitglieder der Landesregierungen, die regionalen Spitzen von Verwaltung, Partei und NS-Juristenbund sowie die höheren Justizbeamten, Richter und Staatsanwälte teilnahmen. Die erwähnte Rede an seiner früheren Wirkungsstätte in München nahm Gürtner zum Anlaß, etwaige Befürchtungen vor einer Überzentralisation und vor kommenden „Massenverschiebungen von Beamten im Reich" zu zerstreuen: Lediglich der juristische Nachwuchs solle zur Festigung der Verbundenheit zwischen den deutschen Stämmen „eine Anzahl von Wanderjahren durchmachen“, wie sie früher bei den Zünften vor Erlangung des Meistertitels üblich gewesen seien. ${ }^{42}$ Hier wie auch vor den Justizangehörigen der anderen süddeutschen Länder würdigte Gürtner die historischen Leistungen der Landesjustizverwaltungen und warb um Vertrauen zur Reichsjustizverwaltung, das ihm als NichtPreußen sicher um so leichter entgegengebracht wurde. ${ }^{43}$ In Hessen, Braunschweig, Anhalt und Lippe vollzog Staatssekretär Freisler im Auftrage Gürtners die Übernahme. In den norddeutschen Ländern erfolgte sie durch den Beauftragten Rothenberger ${ }^{44}$; hier begrüßte Freisler in Schwerin, Rostock, Oldenburg, Bremen und Lübeck die Justizangehörigen lediglich nachträglich aus diesem Anlaß. Schließlich wurde die vollzogene Übernahme der Justizverwaltungen der Abteilung Nord am 25.Januar nochmals in einem besonderen Staatsakt gewürdigt, zu dem Gürtner mit Freisler nach Hamburg kam und bei dem dem Minister vom Hamburgischen Senat die Bilderhandschrift des hamburgischen Stadtrechts von 1497 „als Symbol für das in der hamburgischen Justiz steckende Erbgut" übergeben wurde. ${ }^{45}$ Vom 7. bis 9. Februar besuchten Gürtner und Freisler abschließend noch Dresden, Weimar und das Oberlandesgericht Jena, um anläßlich der auch hier durch Thierack bereits vollzogenen Übernahme mit den örtlichen Spitzen von Staat und Partei Fühlung aufzunehmen und sich die höhe-

$39 \mathrm{Vgl}$. Kapitel III.3.a., S. $245 \mathrm{ff}$.

40 F. Gürtner, Auf dem Wege zur einheitlichen Justiz. Rede des Reichsjustizministers Dr. Gürtner bei der Übernahme der bayerischen Justizverwaltung (DJ 1935, S.81 f.), S.82.

41 So lautete der Titel eines Aufsatzes von Gürtner in der DJ 1934, S. $1523 \mathrm{f}$.

42 DJ 1935, S. 82.

43 Zu den Festakten in München, Stuttgart und Karlsruhe: Die feierliche Übernahme der süddeutschen Justizverwaltungen auf das Reich. Die Kundgebungen in Anwesenheit des Reichsjustizministers Dr. Gürtner (DJ 1935, S. 107 ff.; auch Bericht, a.a.O., S. 75).

44 Für den erkrankten Rothenberger wurde diese Aufgabe von RegDir. Letz übernommen. Vgl. dessen Ber. über seine Rundreise vom 8. und 9.1.1935, Akten der Hamburger Landesjustizverwaltung, LJV VII Aa 1 vol. 1-27 (Arch. der Forschungsstelle für die Geschichte des Nationalsozialismus in Hamburg, Best. 3301).

45 Vgl. Die feierliche Ưbernahme der Justizverwaltungen der norddeutschen Länder auf das Reich. Die Kundgebung in Anwesenheit des Reichsministers der Justiz Dr. Gürtner (DJ 1935, S. 171 ff.), S. 172. 
ren Justizbeamten, Richter und Staatsanwälte vorstellen zu lassen. ${ }^{46}$ Die Festredner auf jenen Feiern zum „Abschied von den Landesjustizverwaltungen“ hätten wohl kaum allerorts so zahlreiche „historische Stunden“ beschworen, wenn sie geahnt hätten, daß es ein gutes Jahrzehnt später in Deutschland wieder Landesjustizministerien geben sollte.

Durch die Verreichlichung verlor auch Hans Frank seine staatlichen Ämter im Justizbereich. Bereits im Dezember 1934 hatte er dem Bayerischen Ministerrat berichtet, daß das Bayerische Staatsministerium der Justiz vom 1. Januar bis 31. März 1935 nur noch als Abwicklungsstelle fungieren werde. ${ }^{47}$ Frank blieb zunächst Minister ohne Geschäftsbereich in der bayerischen Landesregierung. Auch das Amt des Reichsjustizkommissars, das er ein Jahr vorher noch als "dauernde Einrichtung“ bezeichnet hatte ${ }^{48}$, mußte er zur Verfügung stellen. Am 19. Dezember 1934 erhielt er ein Handschreiben Hitlers, in dem dieser ihm für die Tätigkeit als Reichsjustizkommissar Dank und Anerkennung aussprach und „hiermit den Auftrag für beendet“ erklärte. Zugleich ernannte er Frank zum Reichsminister ohne Geschäftsbereich und verwies ihn auf sein verbleibendes Betätigungsfeld im staatlichen Bereich:

„Für die Mitarbeit bei der Erneuerung der Rechtsordnung haben Sie sich in der Akademie des Deutschen Rechts eine vorbildliche, dauernde Einrichtung geschaffen, die Sie in den Stand setzt, ohne Beschränkung auf die Justiz im engeren Sinne bei der Durchsetzung der nationalsozialistischen Weltanschauung auf allen Gebieten der Neugestaltung des Rechts mitzuwirken. “49

Mochte dieses zur Veröffentlichung bestimmte Schreiben ${ }^{50}$ durch die Worte: „ohne Beschränkung auf die Justiz" nach außen hin wie eine Erweiterung der Befugnisse Franks aussehen, so bedeutete es in der Realität die weitgehende Ausschaltung Franks gerade aus der Justizgesetzgebung. Denn Franks Hoffnungen, einmal die zentrale Position für die Mitwirkung der Partei an der staatlichen Gesetzgebung einnehmen und das Reichsjustizkommissariat zur „amtlichen Stelle der Rechtserneuerung“ ausbauen zu können, die allein „die notwendige Verbindung zu den Gesetzgebungsorganen des Reiches" herzustellen hätte ${ }^{51}$, hatte sich längst zerschlagen: durch den Erlaß Hitlers vom 27. Juli 1934 war diese Funktion bereits dem Stab des Stellvertreters des Führers - der späteren Partei-Kanzlei unter Bormann - übertragen worden. ${ }^{52}$ Frank blieben auf dem Gebiet der Justiz nur die Präsidentschaft der Akademie für Deutsches Recht, die auf die praktische Gesetzgebung wenig Einfluß nehmen sollte ${ }^{53}$, und seine Ämter innerhalb der Bewegung, die er 1942 schließlich auch verlor.

46 S. Reichsjustizminister Dr. Gürtner in Sachsen und Thüringen. Kundgebungen in Dresden, Weimar und Jena (DJ 1935, S.249ff.).

47 Meldung des DNB Nr. 2633 vom 19.12.1934 (Akten der RK, BA, Sign. R 43 II/1505).

48 Frank äußerte am 26.10.1933 im Beisein Gürtners vor der Presse, „daß der Reichsjustizkommissar als dauernde Einrichtung identisch sei mit dem Reichsleiter der Rechtsabteilung der NSDAP, so daß auf dem Rechtsgebiet der Einbau der weltanschaulichen Grundlage der NSDAP in den Staat sich am einfachsten vollziehe" (VB, Südd. Ausgabe, v. 27.10.1933, S. 1).

49 Text des Briefes s. DR 1935, S.18.

so Das Schreiben wurde noch am selben Tag vom DNB verbreitet und am nächsten Tag auch im VB (Nr. 344 v. 20.12.1934) abgedruckt.

s1 Vgl. den Abschnitt „Das Reichsjustizkommissariat“ in: H. Frank, Nationalsozialistisches Handbuch für Recht und Gesetzgebung, S. 1584.

52 Akten der Reichskanzlei. Die Regierung Hitler. Teil I, Bd. 2 [s. Kapitel I, Anm.3], Dok. Nr.380, S. 1381 f., und BA, Sign. R 43 II/694. Vgl. dazu O. Gauweiler, Rechtseinrichtungen und Rechtsaufgaben der Bewegung, München 1939, S.151f.

33 Vgl. dazu das Kapitel VII. 1., S. $747 \mathrm{f}$. 
Daß nach dem zweiten Überleitungsgesetz die Landesjustizministerien aufgelöst und ihre Zuständigkeiten auf den Reichsjustizminister übertragen, die nachgeordneten Behörden - Gerichte, Staatsanwaltschaften und Strafanstalten - jedoch Einrichtungen der Länder und die Beamten Landesbeamte blieben, die aus dem Haushalt des betreffenden Landes finanziert wurden, konnte von vornherein nur als Übergangslösung gedacht sein. Der nächste Schritt ließ daher auch nicht lange auf sich warten. Am 18.Januar 1935 reichte Gürtner der Reichskanzlei den Entwurf eines „Dritten Gesetzes zur Überleitung der Rechtspflege auf das Reich" für die Beschlußfassung durch das Reichskabinett ein. ${ }^{54}$ Da bei der Ausführung dieses Gesetzes der Haushalt des Reichs belastet wurde, mußte diesmal bei den Vorarbeiten vor allem das Reichsfinanzministerium eingeschaltet werden. Es regte einige Änderungen an, so daß Gürtner der Reichskanzlei am 23. Januar einen neuen Entwurf zugehen lassen mußte, in dem die Vorschläge des Reichsfinanzministers berücksichtigt waren. ${ }^{55}$ In der Kabinettssitzung am Vormittag des 24.Januar 1935 wurde das Gesetz von Hitler gebilligt. ${ }^{56}$

Durch dieses Gesetz ${ }^{57}$ wurden die Justizbehörden der Länder mit Beginn des neuen Rechnungsjahres - d.h. mit dem 1.April 1935 - Reichsbehörden, die Justizbeamten der Länder wurden unmittelbare Reichsbeamte, die Angestellten und Arbeiter der Justizbehörden traten in den Dienst des Reiches $(\S 1)$. Von diesem Datum ab gingen die Einnahmen und Ausgaben für die Landesjustizverwaltungen einschließlich der Ausgaben für Ruhegehälter, Wartegelder und Hinterbliebenenbezüge auf Rechnung des Reichs $(\S 2)$. Gleichzeitig trat das Reich in alle vermögensrechtlichen Pflichten und Rechte ein, die mit der Justizverwaltung der Länder verbunden waren; Grundstücke und bewegliche Sachen der Länder gingen in das Eigentum des Reichs über, wenn sie ausschließlich oder überwiegend von Justizbehörden benutzt wurden. Aus Anlaß dieses Überganges wurden Steuern, Gebühren oder andere Abgaben nicht erhoben (§3). Bis das Beamten-, Besoldungs-, Haushalts- usw. Recht des Reichs eingeführt werden konnte, sollten übergangsweise die entsprechenden Rechts- und Verwaltungsvorschriften des Landes weitergelten. Während so vor allem auch die Landesdisziplinarbehörden für die Beamten zunächst weiter zuständig blieben, sollte sich jedoch die Zuständigkeit für deren Ernennung und Entlassung bereits nach den entsprechenden Bestimmungen für die unmittelbaren Reichsbeamten richten (§ 4). Um die vielfachen Zusammenhänge zwischen den Justizbehörden und anderen Behörden nicht zu stören, wurden die zwischen ihnen bestehenden Beziehungen bis auf weiteres ausdrücklich aufrechterhalten: Soweit Behörden des Reichs, der Länder und Gemeinden für Zwecke der Justizverwaltung Einrichtungen oder Bedienstete zur Verfügung stellten, sollte es dabei bleiben, bis der Reichsjustizminister in Einvernehmen mit den zuständigen Behörden eine andere Regelung traf (§5). So mußten z. B. die Landesbaubehörden die nunmehrigen Reichsjustizbehörden weiterhin fachlich betreuen. Das gleiche galt für den umgekehrten Fall, daß die Justizbehörden für andere Behörden Geschäfte führten (§ 6). In beiden Fällen durften für diese Leistungen keine anderen Entschädigungen als bisher beansprucht werden. Beamten, die in vorgerücktem Lebensalter

\footnotetext{
54 Akten der RK (BA, Sign. R 43 II/1505).

55 A.a.O.

56 Niederschr. der Sitzung (Akten der RK, Regierung Hitler, Bd. II.1, Dok. Nr. 85, S. 324).

57 Drittes Gesetz zur Überleitung der Rechtspflege auf das Reich v. 24.1. 1935 (RGBI. I, S. 68).
} 
standen und sich in die neuen Verwaltungsbestimmungen des Reichs nicht mehr einarbeiten mochten, wurde mit Vollendung des 62 . Lebensjahres der vorzeitige Übertritt in den Ruhestand ermöglicht ( $(7)$. Tauchten bei der Anwendung des Gesetzes Zweifelsfragen auf, z. B. ob eine Behörde Justizbehörde sei oder ob ein Grundstück überwiegend von der Justiz benutzt wurde, so sollte der Reichsjustizminister im Einvernehmen mit dem Reichsinnenminister - in haushalts- oder vermögensrechtlichen Fragen mit dem Reichsfinanzminister - entscheiden können, um langwierige Verhandlungen und Verzögerungen zu vermeiden. Um die Belange des betreffenden Landes zu wahren, sollte er sich in einem solchen Falle zuvor lediglich mit der zuständigen obersten Landesbehörde in Verbindung setzen; seine Entscheidung war jedoch für Gerichte und Verwaltungsbehörden bindend (§ 8). Da das Reich mit der Übernahme der gesamten Justiz den Ländern auch finanzielle Lasten abnahm, mußte der Finanzausgleich zwischen Reich und Ländern neu geregelt werden; und zwar sollten die Anteile eines Landes an den Reichssteuerüberweisungen für jedes Rechnungsjahr um den Zuschußbedarf (d.h. den Unterschiedsbetrag zwischen den Ausgaben und Einnahmen) seiner bisherigen Justizverwaltung gekürzt werden. Dabei sollte der Durchschnitt der Rechnungsjahre 1925 bis 1933 den Maßstab dafür abgeben, was die Länder in der Folgezeit jährlich für ihre Justizverwaltungen hätten aufwenden müssen (§9). Das Gesetz wurde von Hitler und den beteiligten Reichsministern Gürtner, Frick und Graf Schwerin von Krosigk, die auch die erforderlichen Durchführungsvorschriften erlassen konnten $(\S 10)$, unterzeichnet.

\section{Die Übernahme der Justizverwaltung des Saarlandes, der Abschluß der „Verreichlichung“ und der Berliner Staatsakt am 2. April 1935}

Noch ehe das Dritte Überleitungsgesetz realisiert war, hatte das Reichsjustizministerium bereits eine neue Aufgabe zu bewältigen: die Übernahme der Justizverwaltung im Saarland, dessen Bevölkerung sich in der Volksabstimmung vom 13.Januar 1935 für eine Rückkehr zu Deutschland entschieden hatte. Anders als in den übrigen deutschen Ländern vollzog sich die Überleitung der Rechtspflege hier gleichzeitig mit der Übernahme aller Verwaltungszweige auf das Reich; deshalb galten für die Justiz hier dieselben Überleitungsbestimmungen wie für die anderen Ressorts. Nach dem von Hitler und Frick unterzeichneten Gesetz über die vorläufige Verwaltung des Saarlandes vom 30.Januar $1935^{1}$ wurden neben allen anderen Landesbehörden auch die Justizbehörden ab 1. März Einrichtungen des Reichs und ihre Beamten unmittelbare Reichsbeamte - übrigens die ersten Reichsbeamten in der Außenverwaltung der Justiz, da ihre Berufsgenossen im Reich diesen Status erst vier Wochen später erhielten. Das Saarland wurde dem Oberlandesgericht Köln zugeteilt ${ }^{2}$; zur Wahrnehmung der Aufgaben des gleichzeitig aufgelösten saarländischen Obersten Gerichtshofs wurden

2 Als die NSDAP das Saarland mit der Pfalz zum Gau Saarpfalz zusammenfaßte, wurde das Saarland durch VO v. 21.7.1938 (RGBl. I, S.912) dem OLG-Bezirk Zweibrücken angeschlossen. 
jedoch auswärtige Senate des Oberlandesgerichts Köln in Saarlouis (Saarlautern) eingerichtet. Bis das Behördenrecht des Reichs in der gesamten deutschen Justizverwaltung eingeführt werden konnte, wurden die saarländischen Justizbeamten zunächst preußischem Recht unterstellt. Nur die Zuständigkeit für ihre Ernennung und Entlassung richtete sich bereits nach den für unmittelbare Reichsbeamte geltenden Bestimmungen. ${ }^{3}$

Die Übernahme der saarländischen Justizverwaltung - deren Geschäfte bisher durch die vom Völkerbund eingesetzte internationale Regierungskommission wahrgenommen worden waren ${ }^{4}$ - wurde am 1. März 1935 im Reichsjustizministerium in der Wilhelmstraße lediglich durch einen Gemeinschaftsempfang der Rundfunkübertragung vom feierlichen Übergabeakt in Saarbrücken begangen. ${ }^{5}$ Den ersten offiziellen Besuch stattete Gürtner mit seinen beiden Staatssekretären Saarbrücken erst am 23. Mai ab.

In seiner Saarbrückener Rede betonte er, daß im Saarland „15 Jahre lang die Rechtsentwicklung ohne Zusammenhang mit dem übrigen deutschen Volke ihren Weg gegangen“ sei und daß sich daher „die Angleichung nicht ohne Schwierigkeiten“ vollziehe. ${ }^{6}$ In der Tat galt im Saargebiet auf vielen Sachgebieten noch das alte Recht, das beim Waffenstillstand im November 1918 in Kraft gewesen war; auch das in der Zwischenzeit von der Regierungskommission eingeführte neue Recht unterschied sich wesentlich vom nationalsozialistischen. Daher konnte die Rechtsangleichung nur schonend und schrittweise erfolgen, da eine Überschwemmung der Behörden mit neuem Recht nur Rechtsunsicherheit heraufbeschworen hätte. Auf dem Gebiet der Justiz wurden zunächst nur die dringlichsten Reichsgesetze wie z.B. das Reichsstrafgesetzbuch nebst den Strafgesetznovellen, die im Reich geltende Fassung des Bürgerlichen Gesetzbuchs und des Handelsgesetzbuchs, das neue Zwangsvollstreckungs-, Wechsel- und Scheckrecht und die erneuerte Zivilprozeßordnung - vielfach noch mit Ausnahmebestimmungen - eingeführt. ${ }^{7}$ Im Jahre 1935 erließ der Reichsjustizminister in seinem Geschäftsbereich rund 25 Verordnungen, die Reichsrecht auf das Saargebiet übertrugen und für das Ministerium einen ziemlichen Arbeitsanfall bedeuteten.

Im Reich selbst war die Zeit bis zum 1.April 1935 der Auflösung der territorialen „Abteilungen“ des Ministeriums und der Einführung der Reichshaushaltsordnung und der Wirtschaftsbestimmungen für Reichsbehörden in der Justizverwaltung ${ }^{8}$, der Ưberführung der Justizbeamten in die Reichsbesoldungsordnung' ${ }^{9}$, der Regelung ihrer

${ }^{3}$ VO über die vorläufige Regelung der Gerichtsverfassung im Saarland v. 22.2.1935 (DJ 1935, S.315). Die preußischen Verwaltungsbestimmungen wurden auch in den Amtsgerichtsbezirken St. Ingbert, Homburg und Blieskastel eingeführt, die als Teile der bayerischen Rheinpfalz seinerzeit dem Saarland zugeteilt und der Sonderverwaltung des Völkerbundes unterstellt worden waren. Für die dortigen Notare galten jedoch wiederum die bayerischen Bestimmungen für Notare.

4 Die „Direktion der Justizverwaltung“ stand unter der Leitung des südslawischen Mitgliedes der Regierungskommission Zoričić.

5 S. Saarfeier und Verleihung der Ehrenkreuze im Justizministerium (DJ 1935, S. 384).

6 S. Reichsjustizminister Dr. Gürtner besucht deutsche Justizbehörden (DJ 1935, S.813 ff.), S.814.

7 Vgl. dazu die Verordnungen vom 21./22. 2.1935 (DJ 1935, S. $316 \mathrm{ff}$.) sowie die Beitrãge der zuständigen Sachbearbeiter des RJM (ebenda, S. 324 ff.). Durch die VO v. 8.7.1935 (RGBl. I, S. 1018) wurden rückwirkend ab 1.3. 1935 auch die Vorschriften des Ersten und Dritten Überleitungsgesetzes sinngemäß eingeführt.

8 VO v. 20.3.1935 (RGBl. I, S. 406) und AV d. RJM v. 27.3.1935 (DJ 1935, S. 480).

9 VO zur Vorbereitung der Utberführung der bisherigen Landesjustizbeamten in die Reichsbesoldungsordnung v. 23.3.1935 (RGBI. I, S. 429). 
Laufbahn ${ }^{10}$, ihres Dienststrafrechts ${ }^{11}$ usw. gewidmet. Nachdem das Recht zur Ernennung und Entlassung der Reichsbeamten durch Hitlers Erlaß vom 1. Februar 1935 geregelt war ${ }^{12}$, konnte Gürtner nun auch bestimmen, in welchem Umfang er sich die ihm übertragene Ausübung dieses Rechtes selbst vorbehielt oder sie an die Leiter der höheren Justizbehörden weiterdelegierte ${ }^{13}$; auch das Verfahren bei der Stellenbesetzung konnte festgelegt werden. ${ }^{14}$ Die „Verordnung zur einheitlichen Regelung der Gerichtsverfassung "15 schuf eine einheitliche Grundlage für die Erledigung der Verwaltungs- und Dienstaufsichtsgeschäfte bei den ordentlichen Gerichten, insbesondere bei der Verwaltung der Amtsgerichte, die bislang im Gerichtsverfassungsgesetz weniger straff geregelt war. Der einheitlichen Organisation der ordentlichen Gerichtsbarkeit mußte auch das seit 1879 bestehende Bayerische Oberste Landesgericht weichen, dessen Zuständigkeiten teils auf das Reichsgericht, teils auf das Oberlandesgericht München übergingen. ${ }^{16}$

Mit dem 1.April 1935 wurden die vier Abteilungen Bayern, Sachsen-Thüringen, Württemberg-Baden und Nord aufgehoben und die bislang zu ihrem Geschäftsbereich gehörenden Oberlandesgerichtspräsidenten und Generalstaatsanwälte in allen Angelegenheiten dem Reichsjustizministerium direkt unterstellt. ${ }^{17}$ Neben dem Reichsgericht, dem Volksgerichtshof und dem Reichspatentamt unterstanden dem Ministerium nunmehr 2576 Gerichte und Staatsanwaltschaften sowie 177 Vollzugsanstalten, dazu 968 nebenamtlich geleitete Anstalten, insbesondere Gerichtsgefängnisse. Das Personal betrug 90000 Beamte, Angestellte und Arbeiter, dazu kamen rund 15000 Beamte im Vorbereitungs- und Probedienst, 43000 Versorgungsberechtigte sowie über 19000 Rechtsanwälte und Notare. Der Haushalt belief sich auf 590 Millionen Reichsmark Ausgaben (einschließlich der Versorgungsbezüge) und 220 Millionen Reichsmark Einnahmen; der Grundbesitz überstieg die Summe von 660 Millionen Reichsmark, gerechnet im Vorkriegsneubauwert. ${ }^{18}$

Die Auflösung der territorialen Abteilungen berührte den Aufbau des Ministeriums in Berlin nicht, die anfallende Mehrbelastung wurde durch eine abermalige Berufung von Kräften aus den nicht-preußischen Ländern ausgewogen. ${ }^{19}$ Auch das Preußische Justizministerium hörte nach einer fast 200jährigen Geschichte nunmehr rechtlich zu bestehen auf. Die Übertragung seiner Zuständigkeiten auf den Reichsjustizminister wurde nicht nochmals ausdrücklich in einer gesonderten Bestimmung festgelegt, denn eine solche „wäre, nachdem der Reichsminister der Justiz bereits seit mehreren Mona-

10 Vgl. z. B. die VO über die Laufbahn für das Amt des Richters und Staatsanwalts v. 29.3.1935 (RGBl. I, S. 487).

1 VO zur vorläufigen Regelung des Dienststrafrechts im Bereich der Justizverwaltung v. 15.3.1935 (RGBl. I, S. 379).

12 Erl. des Führers und Reichskanzlers über die Ernennung und Entlassung der Reichsbeamten v. 1.2.1935 (RGBl. I, S.74).

13 Anordnung über die Ernennung und Entlassung der Beamten in der Reichsjustizverwaltung v. 20.3.1935 und AV d. RJM v. 30.3.1935 (beide DJ 1935, S.545)

14 AV des RJM v. 1.4.1935 (DJ 1935, S. 546).

15 Vom 20.3.1935 (RGBl. I, S. 403).

16 VO über Änderungen des Gerichtswesens in Bayern v. 19.3.1935 (RGBl. I, S. 383).

17 AV des RJM v. 28.3.1935 (DJ 1935, S. 491).

18 Vgl. MinDirig. Schneller, Der Aufbau der Reichsjustizverwaltung im Geschäftsbereich der Haushaltsabteilung (DJ 1936, S.11).

19 Vgl. Kapitel III.3.a., S. $245 \mathrm{ff}$. 
ten die preußischen Geschäfte geführt hatte, in der Öffentlichkeit wenig verständlich erschienen “20. Der Zusatz in der dienstlichen Bezeichnung des Reichsjustizministeriums, der sich auf das preußische Ministerium bezog, fiel künftig weg. ${ }^{21}$ Ferner stimmte Gürtner bei den Beschlüssen des Preußischen Staatsministeriums nicht mehr mit. ${ }^{22}$ Auch die Beteiligung an anderen Aufgaben der Landesregierungen, die die bisherigen Landesjustizminister wahrgenommen hatten, fiel von nun ab weg, da sie das Reichsjustizministerium schon wegen der räumlichen Trennung nicht verwirklichen konnte: so z.B. die Rechtsberatung der Landesregierungen. In Ausnahmefällen erklärte sich hier das Ministerium bereit, Beamte als Justitiare abzuordnen. ${ }^{23}$ Auch an der Ausarbeitung von Gesetzen und Rechtsverordnungen der Länder außerhalb des unmittelbaren Justizbereichs war das Reichsjustizministerium nicht mehr im früheren Ausmaß beteiligt. Wurden dabei neue Strafbestimmungen geschaffen oder sonst Justizinteressen berührt, sollten die Landesregierungen allerdings vor der Beschlußfassung mit dem Reichsjustizminister Verbindung aufnehmen. ${ }^{24}$ Die nachträgliche $\mathrm{Zu}$ stimmung zu Landesgesetzen durch den zuständigen Reichsminister war seit Februar 1934 ohnehin vorgeschrieben. ${ }^{25}$ Eine Sonderregelung galt für Preußen: Am 1.April 1935 richtete Göring als Preußischer Ministerpräsident ein Schreiben an Gürtner, in dem er ihn bat, weiterhin an der preußischen Gesetzgebung mitzuwirken und auch in Zukunft an den Beratungen des Staatsministeriums in Berlin teilzunehmen. ${ }^{26}$ Gürtner sagte seine Mitarbeit zu und nahm zu den umlaufenden Beschlußsachen der preußischen Staatsminister weiter Stellung. In einer Hausverfügung ordnete er an, daß die preußischen Staatsministerialsachen wie bisher daraufhin zu prüfen seien, ob gegen Vorlagen vom Standpunkt des Reichsjustizministeriums aus Bedenken bestünden. ${ }^{27}$

Nachdem das Dritte Überleitungsgesetz in Kraft getreten war, sollte noch jahrelange Arbeit erforderlich sein, bis bei der Behördenverwaltung an die Stelle sämtlicher Länderbestimmungen, die einstweilen sinngemäß weiter angewendet wurden, einheitliche Reichsvorschriften getreten waren. So blieben z. B. bestimmte Maßnahmen allein in Erwartung des neuen Deutschen Beamtengesetzes zurückgestellt ${ }^{28}$, das aber erst im Januar 1937 verabschiedet werden konnte. Auch wegen des Übergangs von Grundstücken und anderem Eigentum sowie wegen damit verbundener Leistungen der Länder an die Reichsjustizverwaltung gab es bis in den Krieg hinein Auseinandersetzungen mit den Landesfinanzverwaltungen. ${ }^{29}$ Von diesen Nachhutgefechten abgesehen, war jedoch das Ziel der Verreichlichung der Justizverwaltung am 1. April 1935 er-

${ }^{20}$ F. Schlegelberger, Der Weg ins Reich, in: 200 Jahre Dienst am Recht. Gedenkschrift aus Anlaß des 200jährigen Gründungstages des Preußischen Justizministeriums, herausgegeben vom Reichsminister der Justiz Dr. Franz Gürtner, Berlin 1938, S. 173 ff., 188.

${ }^{21}$ Schr. Schlegelbergers an die obersten Reichsbehörden v. 9.4.1935, Akten des RFiM (BA, Sign. R 2/23901).

$22 \mathrm{Zu}$ seiner weiteren Mitwirkung vgl. im folgenden.

23 Rundschr. Schlegelbergers an die nichtpreußischen Landesregierungen v. 23.4.1935 (Akten des RJM, BA, Sign. R 22/12) und AV des RJM v. 28.12.1934 (DJ 1935, S. 5).

${ }^{24}$ RdSchr. Schlegelbergers, a.a.O.

25 $\S 3$ der 1. VO über den Neuaufbau des Reichs v. 2.2.1934 (RGBl. I, S. 81).

26 Das Schreiben ist abgedruckt in DJ 1935, S. 543.

${ }^{27}$ Hausverf. v. 13.4.1935 (Akten des RJM, BA, Sign. R 22/14).

${ }^{28}$ MinDir. Nadler, Die Arbeit der Personalabteilung des Reichsjustizministeriums im Jahre 1935 (DJ 1936, S. 3 f.).

29 S. dazu die Akten des RFiM, Abt. I, Gruppe Justiz, Überleitung der Rechtspflege auf das Reich (BA, Sign. R 2/24093-24097). 
reicht: neben die Verwaltungen der Reichspost, der Reichswehr, der Reichsfinanz und der Reichsbahn trat nun die aus sechzehn Landesjustizverwaltungen zusammengeschmolzene Reichsjustiz „als die neue fünfte Säule des deutschen Einheitsstaates“30. Die Fugen dieser Säule auf Landesebene waren nunmehr weitgehend geschlossen, wer auf das Innere einwirken wollte, mußte den Weg über das Kapitell nehmen - mit Ausnahme bei der Personalpolitik: da sich die Gauleiter schon bald darüber beschwerten, daß sie in ihrem Machtbereich Personalwünsche nicht mehr durchzusetzen vermochten, weil die Besetzung der Richter- und Staatsanwaltsstellen nunmehr auf oberster Ebene erfolgte, wurde ihnen durch eine Sonderabmachung zwischen Justiz und Parteiführung vom November 1935 auf diesem Gebiet wieder stärkerer Einfluß eingeräumt. ${ }^{31}$ Die allgemeine Tendenz zur Zentralisierung war Teil jenes innenpolitischen Evolutionsprozesses seit 1934, bei dem die „revolutionäre“ Phase durch eine Phase abgelöst wurde, in der die Effektivität des Staatsapparats gesteigert und die Ministerialbürokratie gestärkt wurde. Diese Phase zeichnete sich durch einen generellen Kompetenzzuwachs der zentralen Reichsressorts und durch eine vorübergehende Einschränkung der Machtbefugnisse der Gauleiter aus. ${ }^{32}$ Das schloß jedoch gelegentliche Versuche der Gauleiter nicht aus, in politisch relevanten Fällen unmittelbar auf die Tätigkeit der Gerichte einwirken zu wollen. ${ }^{33}$

Aus Anlaß der Verreichlichung befahl Gürtner die Beflaggung sämtlicher Justizbehörden. Am 2. April hatte die Justiz ihren großen Tag: als symbolischer Abschluß der Verreichlichung fand am Nachmittag dieses Tages im Staatlichen Opernhaus zu Berlin ein Staatsakt statt, an dem Hitler und die Führung von Reich, Ländern und Partei sowie Vertreter der Wehrmacht, der Wissenschaft und der Kunst teilnahmen. Von allen Teilen des Reichs kamen die höheren Richter und Staatsanwälte sowie Abordnungen der übrigen Beamten, Angestellten und Arbeiter der Justiz, ferner Vertreter der Rechtsanwaltschaft, der Notare, des Deutschen Beamtenbundes, des BNSDJ und der Akademie für Deutsches Recht nach Berlin. Um dem Akt ein besonders feierliches Gepräge zu geben, zogen von der Friedrich-Wilhelm-Universität aus die Präsidenten und Richter des Reichsgerichts und des Volksgerichtshofs, die Mitglieder der Oberreichsanwaltschaft, sämtliche Oberlandesgerichtspräsidenten, Generalstaatsanwälte, Landgerichtspräsidenten und Oberstaatsanwälte - rund 700 deutsche Richter und Staatsanwälte - sowie die Dekane aller juristischen Fakultäten des Reichs in Amtstracht und geschlossener Prozession über die Linden in die Oper ein, allen voran Reichsgerichtspräsident Bumke in pelzbesetzter roter Robe. Diese prunkvolle Demonstration und Hervorhebung der neu geschaffenen Reichsjustiz, bei der deren höchste Würdenträger vor den Repräsentanten von Staat und Bewegung im wahrsten

30 S. die „Wochenschau“ von MinRat Pätzold in DJ 1935, S. 494.

31 Vgl. dazu Kapitel III.1.d., S. 207 f.

$32 \mathrm{Zu}$ diesem Problem s. P. Hüttenberger, Die Gauleiter. Studie zum Wandel des Machtgefüges in der NSDAP, Stuttgart 1969, bes. S.107 ff. In einer Denkschrift an Hitler vom 27.1.1936 beschwerte sich der thüringische Gauleiter und Reichsstatthalter Sauckel darüber, daß die Reichsstatthalter über die Gesetzgebungs- und Organisationspläne der Reichsministerien nur noch ungenügend informiert wurden, und führte bezüglich der Justiz aus: „Von allen vorbereitenden Maßnahmen des Reiches zur Verreichlichung der Justiz, auch solange sie noch der vom Reichsstatthalter zu betreuenden und zu überwachenden Landesregierung angehörte, bis zu ihrer endgültigen Überführung auf das Reich hat der Statthalter dieses Reiches nie etwas mitgeteilt bekommen.“ (Akten der RK, BA, Sign. R 43 II/494).

33 Vgl. z. B. Kapitel IV.3., S. 370. 
Sinne des Wortes „auf der Staatsbühne“ agieren durften ${ }^{34}$, konnte jedoch über die wahre Stellung der Justiz im nationalsozialistischen Staat nicht hinwegtäuschen. Daß diese Justiz lediglich ein Instrument der nationalsozialistischen Staatsführung zu sein hatte und ihren Trägern die Rolle von Fachleuten zugedacht war, deren sich die Machthaber bedienten, um ihren Willen durchzusetzen, wurde in der anschließenden Rede Görings als Preußischer Ministerpräsident abermals deutlich. In dieser Rede, mit der Göring die preußische Justizverwaltung dem Reich übergab, würdigte er zunächst die Verdienste Kerrls, der "die größte deutsche Justizverwaltung von den Schlacken einer vergangenen Epoche" gereinigt und damit eine wesentliche Voraussetzung für die Verreichlichung der Justiz geschaffen habe. Die neu gestaltete äußere Form müsse aber jetzt von nationalsozialistischem Geist erfüllt werden, um den „nationalsozialistischen Rechtsstaat“ aufzurichten, dessen Aufgabe es allerdings nicht mehr sei, „das Individuum gegen Einwirkungen aller Art von seiten der Obrigkeit in möglichst weitem Umfang zu schützen“. Die Forderung, daß die Justiz gegenüber Freund und Feind eine unterschiedliche Haltung an den Tag legen müsse, kleidete Göring in die Worte, daß die Justiz "gegen den inneren Staats- und Volksfeind“ unerbittlich einschreiten müsse, während ,aufrechte Männer, die der Stimme ihres Blutes treu blieben“ keinesfalls „zu drakonischen Strafen verurteilt werden“ dürften. Nachdem Göring auch noch der Verdienste des „alten und bewährten nationalsozialistischen Mitkämpfers“ Hans Frank um die Vereinheitlichung der Justiz gedacht hatte, dankte er schließlich Gürtner und seinen Mitarbeitern, die bei dieser Aufgabe hätten „letzte Hand anlegen dürfen“ (') und den „Auftrag des Führers mit Umsicht und Energie in kurzer Zeit durchgeführt" hätten. ${ }^{35}$

Die Festrede Gürtners war sowohl für sein politisches wie für sein Rechtsdenken charakteristisch. Auf der einen Seite begrüßte er als deutschnational Gesinnter die Tatsache, daß Hitlers Zielsetzung und der Elan der nationalsozialistischen Bewegung den Aufbau einer schlagkräftigen Reichsjustiz ermöglicht hatten - sein in dieser Rede ausgesprochener Dank an Hitler darf daher durchaus als echt empfunden angesehen werden. Auf der anderen Seite aber sprach er eine Mahnung aus, die sein Bestreben kennzeichnet, die „revolutionären“ ungesetzlichen Ausschreitungen des Regimes künftig auszuschalten und die Entwicklung in den Bahnen normativen Handelns nach positivem Recht zu halten - allerdings unbeschadet der Frage, ob dieses Recht vom Standpunkt überstaatlicher Gerechtigkeit aus nicht vielfach Unrecht bedeutete. Nachdem er Göring für die ihm und seinen Mitarbeitern gezollte Anerkennung gedankt hatte, erinnerte er die Anwesenden in eindringlichen Worten daran,

„daß das Ansehen und die Ehre eines Volkes in der Welt ebenso wie von seiner Waffenfähigkeit und Wehrmacht, von der Geltung und Achtung des Rechts abhängt. Wir glauben aber auch daran, daß innerhalb der Nation echte Volksgemeinschaft nur auf dem Boden des Rechts stehen kann. Denn nur auf diesem Boden gedeiht das Vertrauen der Volksgenossen untereinander und zur Führung und ruht die Sicherheit, die zum Aufbau unseres völkischen Lebens, nicht zuletzt der Wirtschaft, unentbehrlich ist.“

34 Die Chefpräsidenten des Reichsgerichts und der Oberlandesgerichte, der Oberreichsanwalt und die Generalstaatsanwälte erschienen auf der Bühne der Staatsoper und nahmen dort während des Staatsaktes Platz. Einen Bericht über die Feierlichkeiten und die in der Staatsoper gehaltenen Reden gibt der VB, Südd. Ausgabe, vom 3.4.1935, S. 1 und 3.

35 Hermann Göring über die Vereinheitlichung des Rechtswesens. Die Rede des Preußischen Ministerpräsidenten beim Staatsakt (DJ 1935, S. 536 ff.). 
Anschließend ging Gürtner auf die Geschichte der deutschen Justiz ein, hob hervor, daß erst das Dritte Reich den Weg zu einer einheitlichen Reichsjustiz geöffnet habe, und umriß die Etappen der Verreichlichung. Die Änderung des Fluidums in seiner Behörde, die die Hereinnahme des preußischen Ministeriums mit seinem fanatischen Staatssekretär Roland Freisler bewirkt hatte - dessen Geschäftigkeit er mit einem gewissen Unbehagen betrachtete und den er in privatem Kreise „Orlando furioso" $\mathrm{zu}$ nennen pflegte ${ }^{36}-$, umschrieb er auf seine Weise:

„Damit ist in das Reichsjustizministerium, das durch alle Stürme der letzten Vergangenheit sein stolzes Erbe mit allen Kräften gehütet hatte, die vorwärts drängende, fast unbändige Kraft eingeströmt, wie sie sich in dem damaligen Preußischen Justizministerium und in der Person des damaligen Preußischen und jetzigen Reichsstaatssekretärs Dr. Freisler verkörperte.“

Gürtner äußerte die Hoffnung, daß sich die Zusammenarbeit mit der Partei durch die Einrichtung der zentralen Reichsjustizbehörde - die von nun an eine Erörterung aller zwischen ihren nachgeordneten Behörden und örtlichen Parteifunktionären auftretenden Dissonanzen auf oberster Ebene ermöglichte - künftig leichter gestalten werde. Anschließend dankte Gürtner ,in erster Linie dem Führer, der dem deutschen Volke die Rechtseinheit gegeben und durch seinen Entschluß unsere Arbeit beflügelt hat", ferner Göring sowie allen Stellen und Mitarbeitern, die an der Verreichlichung mitgewirkt hatten. Er erinnerte an die geschichtlichen Leistungen der Landesjustizverwaltungen, an die Verantwortung, die die Übernahme dieses Erbes durch das Reich bedeute, und schloß mit den Worten:

„So können wir mit gutem Gewissen dem deutschen Volke und seinem Führer beute feierlich geloben, unsern Stolz und unsere Kraft daranzusetzen, treue Hüter des Rechts zu sein und dadurch in unserer Weise der Ehre und dem Glück des deutschen Volkes zu dienen. ${ }^{\text {“37 }}$

Dieses Gelöbnis zum Dienst am Recht, wie er es verstand, dürfte Gürtner für seine Person durchaus ernst gemeint haben - ob er es im Hinblick auf Erfüllung mit gutem Gewissen abgab, mag angesichts seiner bisherigen Erfahrungen dahingestellt bleiben. Als Hitler ihm am Ende des Staatsaktes in der Ehrenloge der Oper dankend die Hand schüttelte und beide von immer wieder hervorbrechenden Heil-Rufen umtost wurden, wird Gürtner sicher von einem erhebenden Gefühl des Erfolgs erfüllt gewesen sein, in das sich allerdings auch Sorge um die zukünftige Entwicklung der Justiz gemischt haben dürfte: Das Instrument der Reichsjustiz war geschaffen; daß die politische Führung an seine Handhabung Forderungen und Erwartungen knüpfte, deren Erfüllung für die Justiz grundlegende Probleme aufwarf, war ihm zu diesem Zeitpunkt längst klargeworden.

36 Lutz Graf Schwerin von Krosigk, Es geschah in Deutschland. Menschenbilder unseres Jahrhunderts, Tübingen u. Stuttgart 1951, S.321.

37 Rede Gürtners vgl. DJ 1935, S. 539 f. Hervorheb. im Original. Als dritter Redner sprach Frick, der die Bedeutung der Verreichlichung der Justiz für den gesamten Reichsneuaufbau und die andersgearteten Verhältnisse bei der Verreichlichung der allgemeinen und inneren Verwaltung hervorhob. Vgl., a.a.O., S. $541 \mathrm{ff}$. 